\title{
Strategies for increasing lipid accumulation and recovery from Y. lipolytica: A review ${ }^{\text {光 }}$
}

\author{
Sally El Kantar*, Anissa Khelfa, Eugène Vorobiev and Mohamed Koubaa* ${ }^{*}$ \\ Université de technologie de Compiègne, ESCOM, TIMR (Integrated Transformations of Renewable Matter), Centre de recherche \\ Royallieu, CS 60 319, 60203 Compiègne Cedex, France
}

Received 22 June 2021 - Accepted 21 October 2021

\begin{abstract}
Microbial-based biodiesel is produced by transesterification of lipids extracted from microbial cells, and is considered as a potential replacement of fossil fuel due to its advantages in reducing greenhouse gas emissions. Yarrowia lipolytica is one of the most studied oleaginous yeasts able to produce lipids under some fermentation conditions and is considered as a potential industrial host for biodiesel production. Several approaches have been evaluated to increase the economical attraction of biodiesel production from Y. lipolytica lipids. In this review, we highlighted the different strategies reported in the literature, allowing this yeast to achieve high lipid accumulation. These include metabolic engineering strategies, the use of lowcost effective substrates, and the optimization of the cultivation conditions for higher lipid productivity and less operating cost. We also summarized the most effective cell disruption technologies that improve the extraction efficiencies of lipids from Y. lipolytica.
\end{abstract}

Keywords: Y. lipolytica / microbial oils / lipid accumulation / lipid extraction / biodiesel

Résumé - Les stratégies adoptées pour améliorer l'accumulation et l'extraction des lipides à partir de Y. lipolytica. Le biodiesel d'origine microbienne est produit par transestérification de lipides extraits de cellules microbiennes et est considéré comme un substitut potentiel des combustibles fossiles en raison de ses avantages dans la réduction des émissions de gaz à effet de serre. Yarrowia lipolytica est l'une des levures oléagineuses les plus étudiées capables de produire des lipides dans certaines conditions de fermentation et est considérée comme un hôte industriel potentiel pour la production de biodiesel. Plusieurs approches ont été évaluées pour augmenter l'attrait économique de la production de biodiesel à partir des lipides de Y. lipolytica. Dans cette revue, nous avons mis en évidence les différentes stratégies rapportées dans la littérature, permettant à cette levure d'atteindre une accumulation élevée de lipides. Ceux-ci incluent des stratégies d'ingénierie métabolique, l'utilisation de substrats carbonés et azotés à faible coût et l'optimisation des conditions de culture pour une productivité lipidique plus élevée et des coûts d'exploitation plus faibles. Nous avons également résumé les technologies de lyse cellulaire les plus efficaces qui améliorent l'efficacité d'extraction des lipides de Y. lipolytica.

Mots clés : Y. lipolytica / huiles microbiennes / accumulation des lipides / extraction des lipides / biodiesel

\section{Highlights}

- The potential use of Y. lipolytica as a promising host for biodiesel production is highlighted.

- Biosynthesis and degradation pathways of lipids in Y. lipolytica are described.

\footnotetext{
Contribution to the Topical Issue "Green and white biotechnologies in the fields of lipids and oil- and proteincrops / Biotechnologies vertes et blanches dans les domaines des lipides et oléoprotéagineux". *Correspondences: m. koubaa@escom.fr; sally.el-kantar@utc.fr
}

- Strategies to improve the economical attraction for microbial oil production in terms of higher lipid productivity and downstream recovery are discussed.

\section{Introduction}

Fossil fuels are commonly used as a primary source of non-renewable energy. Their combustion releases large amounts of greenhouse gases, which negatively contributes to global warming. Concerns about climate change and the quick exhaustion of fossil fuel in the near future have driven research on the production of renewable biofuels as 
alternatives (Mat Aron et al., 2020). First, second and third generation biofuels are obtained depending on the raw material and the technology used for their production (Singh et al., 2011). Ethanol produced by fermenting sugar extracted from edible feed-stocks or biodiesel obtained by transesterification of vegetable oils extracted from plants are examples of first generation biofuels (Tan et al., 2010; Singh et al., 2011; Xie, 2017). The main limitation of first generation biofuels is the use of edible feed-stocks such as sugarcane and corn starch that can present a serious conflict with food industries (Datta et al., 2019). Besides competition with food crops, the cultivation of biofuel crops requires large amounts of land area, fertilizers and water, which result in a high production cost (Paschalidou et al., 2016; Enamala et al., 2018). Therefore, the use of nonedible biomass such as agricultural lignocellulosic biomass is favored for the production of second-generation biofuels. However, the production of lignocellulosic biofuels requires complicated pretreatment of the biomass to obtain fermentable sugars, consequently compromising its economic feasibility (Paschalidou et al., 2016; Ali et al., 2020). Consequently, third generation biofuels obtained from microorganisms such as bacteria, yeasts or microalgae have received increasing attention as sustainable and renewable alternatives to plantbased oils (Abghari and Chen, 2014). Microalgae have shown a promise potential to be used as a source for biofuels production. However, their usage is still limited due to the high cost of cultivation, low biomass concentration and the lack of genetic engineering and transformation tools to create dependable models of algal strains (Li et al., 2008; Gimpel et al., 2015; Xue et al., 2021). Compared to algae, bacteria have a higher growth rate and their cultivation is easier but they accumulate lipids in their membrane which make them difficult to extract (Meng et al., 2009). Therefore, among the oleaginous microorganisms, yeasts are the most effective in terms of lipid accumulation (Darvishi et al., 2017).

Yarrowia lipolytica is a non-conventional yeast which has received particular interest for single cell oil production because of its easily manipulated genome and its extensively studied metabolism which permit the engineering of high lipid accumulation species (Ledesma-Amaro et al., 2015). Y. lipolytica belongs to the Ascomycota phylum. It was previously named as Candida, Endomycopsis or Saccharomycopsis lipolytica. The name "Yarrowia" suggested in 1980, refers to the researcher David Yarrow who has identified this genus. The species name "lipolytica" is related to the ability of the yeast to hydrolyze lipids (Zieniuk and Fabiszewska, 2019). Y. lipolytica strains are isolated from lipid or proteinrich environments such as dairy products and sewage (Carsanba et al., 2018). Y. lipolytica as Generally Recognized As Safe (GRAS) is a non-pathogenic yeast which has the ability to assimilate hydrophilic and hydrophobic substrates to produce value-added byproducts such as long chain dicarboxylic acids mainly used in the synthesis of polyesters and polyamides (Abghari et al., 2017), organic acids (Papanikolaou et al., 2002b) and lipids through de novo and ex novo pathways (Harzevili, 2014; Brabender et al., 2018; Amalia et al., 2020).

Cellular lipid production in Y. lipolytica depends on the genetic background of the strain, the type of substrates used in the culture media and the cultivation conditions. For example, some wild-type strains of Y.lipolytica can accumulate respectively up to $40 \%$ lipids using volatile fatty acids (Fontanille et al., 2012) and 58.5\% lipids using sugar cane bagasse hydrolysate (Tsigie et al., 2011). Moreover, lipid accumulation can exceed $80 \%$ in obese Y. lipolytica strains through genetic modifications (Nicaud, 2012). Concerning growth conditions, nitrogen starvation is known to favor the accumulation of lipids in this yeast. However, most of the wildtype strains cultivated on non-fatty substrates such as glucose or glycerol are not capable to accumulate high lipid levels even under nitrogen limited conditions, since those are degraded to the benefit of organic acids production (Papanikolaou et al., 2002a, 2009). Using a double nitrogen and magnesium limited-media containing glucose or glycerol as substrates, allowed an increase in lipid accumulation while organic acid production was low (Bellou et al., 2016). Lipids produced by Y. lipolytica are accumulated in subcellular compartments called lipid bodies. These lipids consist mainly of triacylglycerols (TAG) and sterol esters and comprise of up to $80 \%$ of unsaturated fatty acids with a high proportion of linoleic acid which gave them an important added value in terms of biofuel production (Gálvez-López et al., 2019). Interestingly, the lipid profile of Y. lipolytica oil can be modified by using low-cost fatty substrates to provide tailor-made lipids (Papanikolaou and Aggelis, 2010). For example, Y. lipolytica cultivated on stearin produced lipids with significant amounts of stearic acid and low amounts of unsaturated fatty acids which gave them a composition similar to that of cocoa butter (Papanikolaou et al., 2001, 2003).

The cost of oil and biodiesel production from Y. lipolytica could be extrapolated from the estimated numbers presented in the study of Koutinas et al. (2014). They found that the cost of biodiesel production from 10000 ton of microbial oil/year is relatively high. About M\$34.1/year are needed for lipid production using glucose ( $\$ 400 /$ ton) as a substrate (Koutinas et al., 2014). Therefore, one of the main challenges for industrial lipid production from Y. lipolytica is to achieve high lipid yields and productivity especially in the engineered strains that use low-cost substrates. Moreover, the improvement of the fermentation and downstream processes represent another challenge to decrease the cost of the overall process (Abghari and Chen, 2014). In this regard, the first part of this review summarizes the strategies applied to boost lipid production in the oleaginous yeast Y. lipolytica. These include metabolic engineering strategies, controlling fermentation conditions (e.g., agitation, $\mathrm{pH}$, etc.), and the use of low-cost effective substrates. The second part provides an overview of the cell disruption technologies that have been used to increase lipid recovery from Y. lipolytica.

\section{Biosynthesis and degradation of lipids in Y. lipolytica}

Y. lipolytica stores its synthesized fatty acids (FAs) in lipid bodies which mainly consist of about $85 \%$ TAG and $8 \%$ sterol esters (SE) (Xie, 2017). It can synthesize TAG via two pathways. The first one is the de novo pathway, which requires hydrophilic substrates (e.g., sugars, organic acids, alcohols, etc.) to produce FAs from the precursor acetyl-CoA, and assemble them into TAG. The second one is the ex novo pathway, which requires the hydrolysis of hydrophobic substrates (e.g., alkanes, TAG, etc.) into FAs and glycerol 


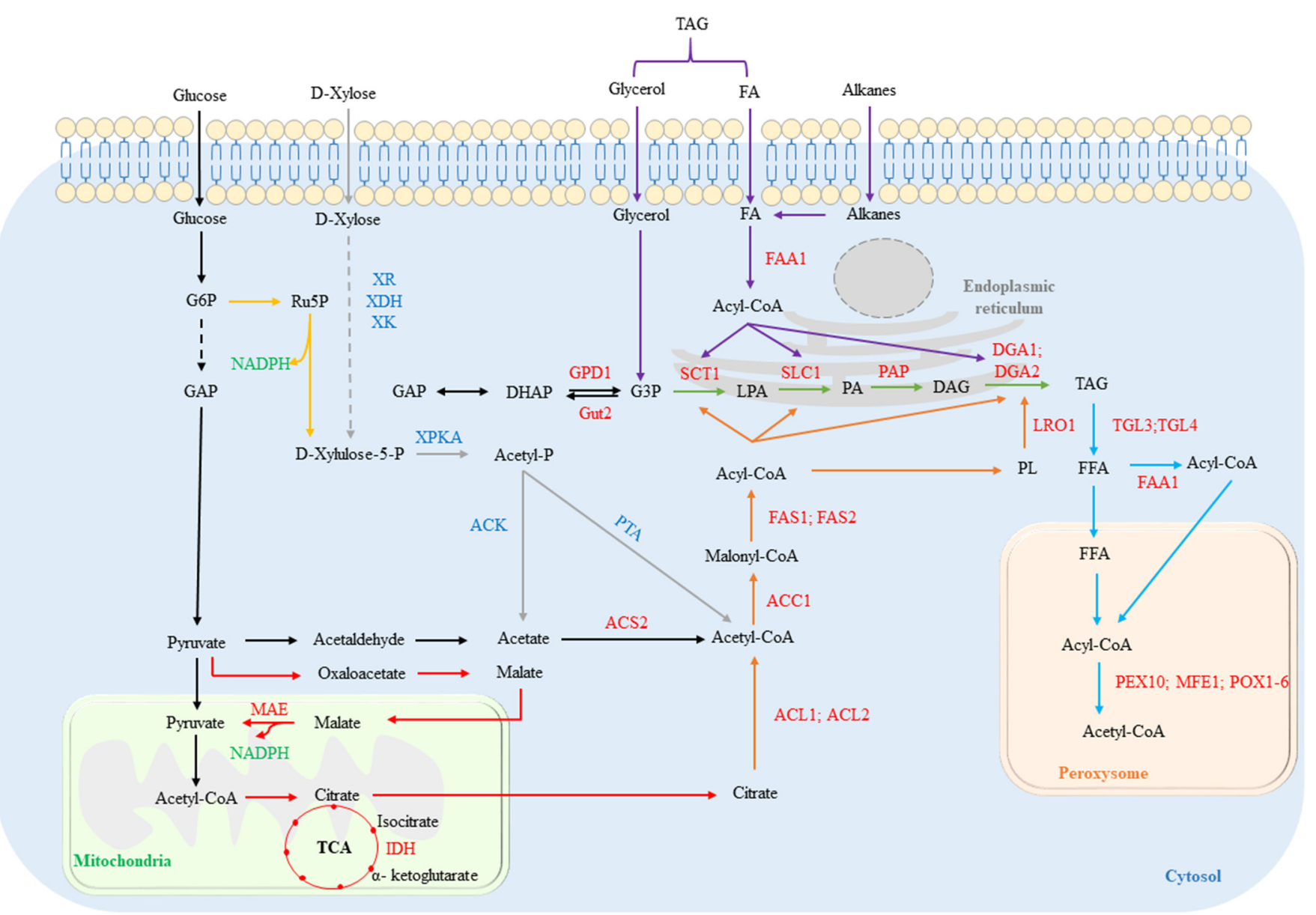

Fig. 1. Synthesis and degradation of TAG in Y. lipolytica. Colored arrows indicate different metabolic pathways: black: glycolysis; grey: xylose pathway; yellow: oxidative pentose phosphate pathway; red: tricarboxylic acid (TCA) cycle and related intermediate reactions; orange: de novo TAG synthesis pathway; purple: ex novo TAG synthesis pathway; green: Kennedy pathway; blue: $\beta$-oxidation pathway. Dashed lines represent multiple metabolic steps. Abbreviations: G6P: glucose-6-phosphate; GAP: glyceraldehyde-3-phosphate; Ru5P: ribulose-5-phosphate; G3P: glycerol-3-phosphate; DHAP: dihydroxyacetone phosphate; LPA: lysophosphatidic acid; PA: phosphatidic acid; DAG: diacylglycerol; TAG: triacylglyceride; FFA: free fatty acid.

and their transport inside the cell for TAG synthesis. Figure 1 summarizes the TAG synthesis pathways in Y. lipolytica.

De novo lipid synthesis is activated under nitrogen-limited conditions and requires carbon substrates such as sugars and alcohols (Mathiazhakan et al., 2016). The decrease in nitrogen amount improves the activity of the enzyme adenosine monophosphate deaminase 1 (AMPD1) which changes adenosine monophosphate (AMP) into inosine monophosphate (IMP) and ammonia. The decrease in AMP concentrations inhibits the action of the enzyme isocitrate dehydrogenase (IDH) responsible for the catalysis of the oxidative decarboxylation reaction of isocitrate, giving $\alpha$-ketoglutarate and carbon dioxide. As a result, the tricarboxylic acid (TCA) cycle is downregulated and the accumulated citrate is transported from the mitochondria into the cytosol. Citrate is then cleaved by ATP-citrate lyase (ACL1 and ACL2) to obtain cytosolic acetyl-CoA, the starting material for lipid synthesis (Lazar et al., 2018; Wang et al., 2020). Several reactions take place in thy cytosol to produce FAs from acetyl-CoA substrate. First, acetyl-CoA carboxylase (ACC1) catalyzes the conversion of acetyl-CoA into malonyl-
CoA. Then the FA synthase complex (FAS1 and FAS2) allows the transformation of malonyl-CoA into acyl-CoA, and the elongation of acyl-CoA to 16 or 18 carbon atoms. In a next step, the obtained C16:0 and C18:0 molecules are transported to the endoplasmic reticulum for further elongation and desaturation (Ledesma-Amaro et al., 2016).

The formation of TAG from three FAs and one glycerol-3phosphate (G3P) follows the Kennedy pathway (Dulermo and Nicaud, 2011). G3P is converted to lysophosphatidic acid (LPA) under the action of G3P acyltransferase (SCT1). LPA is subsequently transformed to phosphatidic acid (PA) by LPA acyltransferase (SLC1). Diacylglycerol (DAG) is then generated through the dephosphorylation of PA by PA phosphatase (PAP). In a final step, TAG can be synthesized by 2 different reactions. The first one is catalyzed by DAG acyltransferase (DGA1 or DGA2) and uses acyl-CoA as the final acyl group donor. The second one is independent from acyl-CoA and uses glycerophospholipid as the acyl group donor under the action of phospholipid DAG acyltransferase (LRO1) (Athenstaedt et al., 2006; Lazar et al., 2018; Wang et al., 2020). 
Y. lipolytica can also synthesize lipids through the ex novo pathway using hydrophobic substrates such as TAG, alkanes and free fatty acids (FFAs) (Lopes et al., 2018). Therefore, many studies have investigated the potential use of this yeast for the valorization of waste and by-products. Animal fats such as tallow (Papanikolaou et al., 2007) and pork fat (Patrignani et al., 2011), vegetable (Louhasakul et al., 2020), cooking (Lopes et al., 2019) and fish (Fabiszewska et al., 2021) oils waste have been used as substrates by Y. lipolytica to produce single cell oil via ex novo pathway. However, some hydrophobic substrates may be toxic to the cells according to their chain length. For example, no growth was observed when alkanes and fatty acids shorter than $\mathrm{C} 9$ are used as carbon sources. Moreover, Y. lipolytica which could use a large variety of fatty acids with a chain length over C9 at concentrations above $3 \%$ is not able to grow on some type of C9 fatty acids such as nonanoic acid at a concentration higher than $0.02 \%$ (Moreno, 2018). Similarly, Y. lipolytica exhibited partiality to short chain FAs (C12:0, C14:0 and C16:0) which were totally consumed in a fermentation media containing glucose, glycerol and stearin (Papanikolaou et al., 2003). The hydrolysis of TAG substrates into glycerol and FFAs is regulated by extracellular lipases (Donot et al., 2014). The hydroxylation of alkanes entering the cells into fatty alcohols occurs in the endoplasmic reticulum via the cytochrome P450dependent alkane monooxygenases. Fatty alcohols are then oxidized to fatty aldehydes and further to FAs respectively by fatty alcohol and fatty aldehyde dehydrogenases (Fukuda, 2013). The obtained FAs are converted to acyl-CoA, the substrate for TAG synthesis, through the acyl-CoA synthetase (FAA1) (Wang et al., 2020).

When carbon is insufficient, TAG degradation occurs to maintain cellular metabolism. In a first step, the intracellular lipases TGL3 and TGL4 degrade TAG into FFAs (Dulermo et al., 2013). Subsequently, the enzyme FAA1 generates acylCoA from the released FAs. Four reactions ensure the cleavage of the long acyl-CoA chains in the peroxisome through the $\beta$-oxidation pathway to obtain acetyl-CoA. The first reaction is catalyzed by six acyl-CoA oxidase (POX1-6) (Beopoulos et al., 2008). The second and third reactions occur under the action of a multifunctional enzyme (MFE1) and the last reaction is catalyzed by 3-ketoacyl-CoA thiolase (POT1) (Blazeck et al., 2014; Lazar et al., 2018).

FAs profile of Y. lipolytica's oil depends on the substrate used in the fermentation media. When tallow, rich in saturated fatty acids, was used as a carbon source, the oil produced by Y. lipolytica was characterized by a high content in saturated FAs (78\% of C18:0 and $17 \%$ of $16: 0)$ and only small amounts of unsaturated FA ( $5 \%$ of $\left.{ }^{\Delta 9} \mathrm{C} 18: 1\right)$ (Papanikolaou et al., 2007). Likewise, when fish oil was used as carbon source, the content of lipids accumulated in the cells was comparable to the substrate and was characterized by the presence of very long chain FAs (Fabiszewska et al., 2021). Similarly, when stearin and hydrolyzed oleic rapeseed oil were used as carbon sources, saturated FAs were the most prevalent and their percentage proportionally increased with that of stearin. This is due to the fact that unsaturated FAs (oleic acid) are utilized for growth needs, while saturated FAs are used for lipid storage (Papanikolaou et al., 2001). However, the use of glucose as co-substrate with stearin favored the production of unsaturated FAs due to the novo FAs biosynthesis (Papanikolaou et al.,
2003). Some studies have also investigated the effect of cultivation conditions ( $\mathrm{pH}$, aeration, nitrogen depletion) on FA profile of cellular lipids (Fabiszewska et al., 2021). For example, higher quantity of oleic acid was obtained when Y. lipolytica was cultivated in highly aerated bioreactor compared to flask trials (Papanikolaou et al., 2007).

\section{Enhancing lipid accumulation in Y. lipolytica}

Various research studies have worked on the improvement of lipid accumulation in Y. lipolytica, by upregulating lipid synthesis or knocking out lipid degradation pathways and modifying the fermentation conditions (e.g., carbon sources, $\mathrm{pH}$, aeration, fermentation mode, etc.). Table 1 summarizes the different strategies and approaches applied to enhance lipid accumulation in Y. lipolytica.

\subsection{Metabolic engineering strategies}

Since wild-type strains of Y. lipolytica are not the most efficient for lipid production (Lazar et al., 2018), researchers have used various metabolic engineering approaches to improve lipid productivity. The enzymes targeted in metabolic engineering strategies are shown in Figure 1.

\subsubsection{Modulating endogenous gene expression}

The potential of Y. lipolytica to accumulate lipids can be improved by adjusting the expression of native genes related to lipid biosynthesis and degradation. Blazeck et al. (2014) adopted a combinatorial strategy to simultaneously overexpress and delete multiple key genes associated to lipid productivity in Y.lipolytica, which generated 57 different genotypes. The most advantageous engineered strain was obtained by eliminating both MFE1 and peroxisome biogenesis (PEX10) genes and overexpressing the DGA1 gene. Compared to the wild-type strain, the engineered strain represented 60-fold improvement in terms of lipid production in the optimized bioreactor conditions (Blazeck et al., 2014). Silverman et al. (2016) studied the effect of overexpressing 44 native genes on lipid biosynthesis in Y. lipolytica. The highest increase in lipid yield $(246 \%)$ was obtained in the strain that overexpressed the DGA2 gene when glucose was used as a substrate (Silverman et al., 2016). Sagnak et al. (2018) evaluated the overexpression of DGA2 gene simultaneously with glycerol-3-phosphate dehydrogenase 1 (GPD1) gene. The resulting strain showed a 4-fold increase in lipid content compared to the control (Sagnak et al., 2018). Similarly, Amalia et al. (2020) overexpressed the LRO1 gene which catalyzes the binding of an acyl group into DAG for the formation of TAG. As a result, the lipid content increased from $7.5 \%$ (wild-type stain) to $12 \%$ (Amalia et al., 2020). Tai and Stephanopoulos (2013) used a push-and-pull strategy by overexpressing simultaneously ACC1 (under the hp4d promoter) and DGA1 (under the TEFin promoter) involved respectively in the first step of FAs synthesis and last step of TAG synthesis pathway. The lipid content increased from $8.7 \%$ in the control to $41 \%$ in the engineered strain that produced $0.143 \mathrm{~g}$ of lipids/L of culture/hour in a $2 \mathrm{~L}$ bioreactor (Tai and 
S. El Kantar et al.: OCL 2021, 28, 51

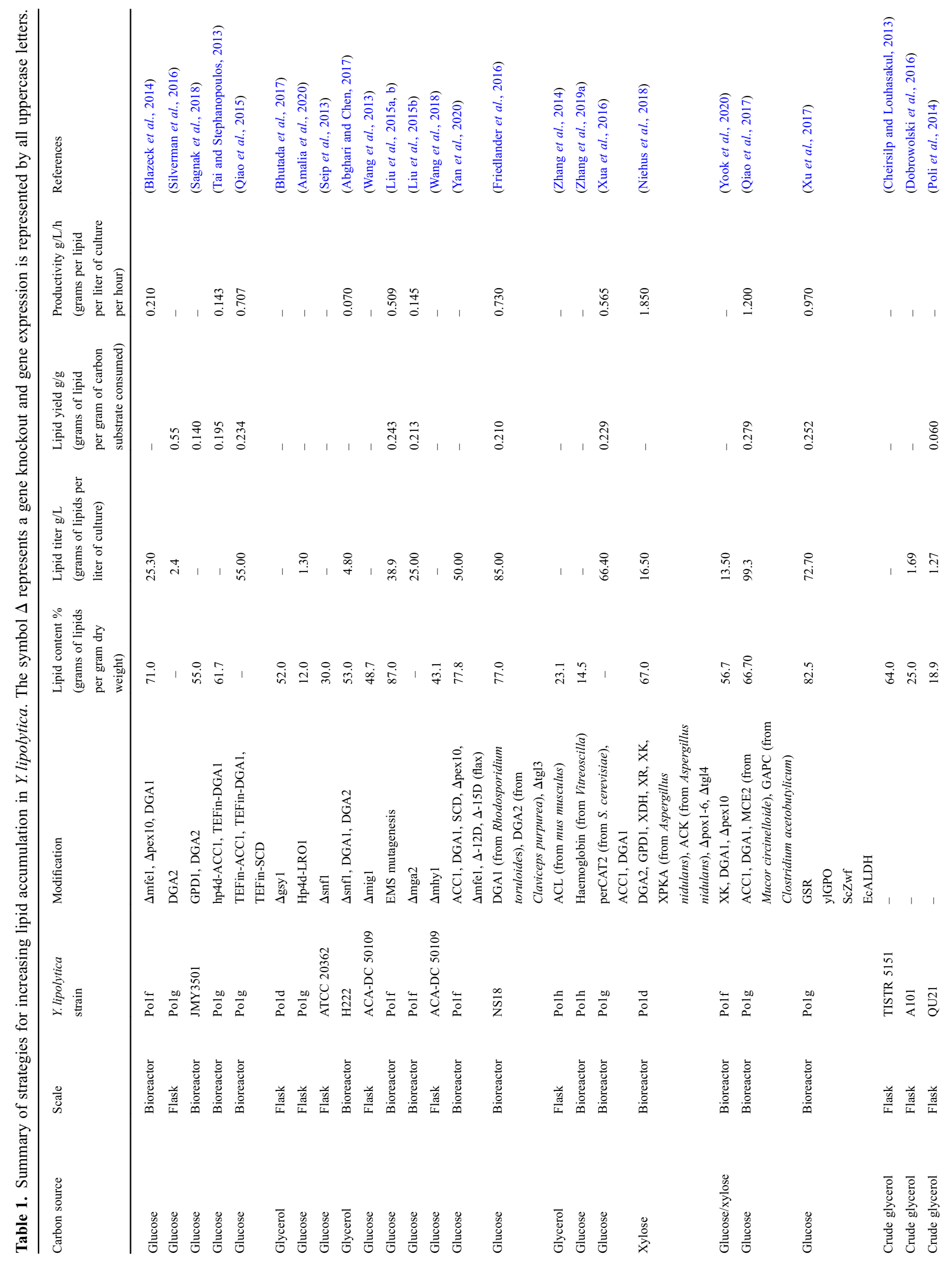


S. El Kantar et al.: OCL 2021, 28, 51

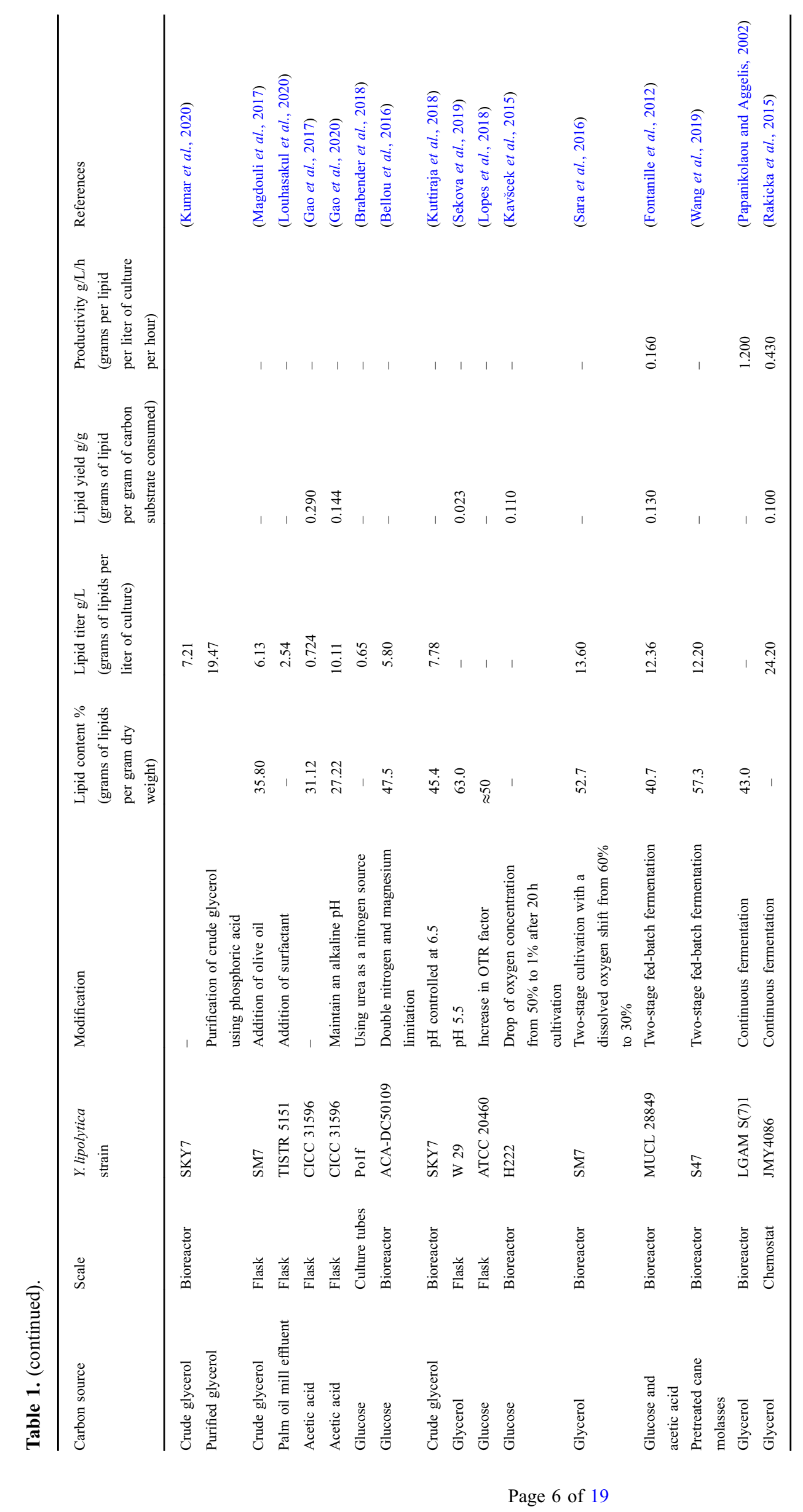


Stephanopoulos, 2013). Qiao et al. (2015) upregulated the simultaneous expression of ACC1, DGA1 and stearoyl-CoA desaturase (SCD) genes in Y. lipolytica. Total lipid yield increased by 2.93 -fold in the engineered strain that showed a maximal lipid productivity close to $1 \mathrm{~g} / \mathrm{L} / \mathrm{h}$ after $78 \mathrm{~h}$ of fermentation in a $1.5 \mathrm{~L}$ bioreactor. The improvement in lipid yield in the engineered strain is due to the upregulated activity of the SCD enzyme that catalyzes the $\Delta 9$-desaturation of saturated FAs to mono-unsaturated FAs. Therefore, the possible allosteric inhibition of ACC1 by saturated FAs could be released, which improves the FAs biosynthetic flux (Qiao et al., 2015). Lipid transporters have also been regulated to increase lipid accumulation in Y. lipolytica. Dulermo et al. (2014) found that Ylfat1 protein is responsible of the export of FAs from lipid bodies. Therefore, $\Delta$ Ylfatl strain accumulated $37 \%$ of lipids compared to $25 \%$ for the parent strain (Dulermo et al., 2014). The knockout of pxal transporter of fatty acylCoA into peroxisome in addition to other fatty acyl-CoA oxidase genes has also resulted in 11-fold improvement of FAs titer compared to the wild-type strain (Ghogare et al., 2020). Finally, redirecting the metabolic flux toward lipid synthesis has effectively enhanced lipid accumulation in Y. lipolytica. Bhutada et al. (2017) deleted the glycogen synthase gene (GSY1) involved in glycogen synthesis in Y. lipolytica strain engineered for high lipid accumulation. They observed a $60 \%$ increase in TAG accumulation with up to 2-fold improvement of desaturated C18 FAs compared to the control strain. They concluded that glycogen synthesis pathway competes with TAG accumulation and the elimination of GSY1 gene redirected the cellular carbon flux from glycogen to TAG synthesis (Bhutada et al., 2017). In another study, Liu et al. (2015a) created spontaneous mutations in the Y. lipolytica strain Po1f $\Delta$ pex10 $\Delta m f e l$ and studied the strain E26 that presented the highest lipid content. The results of genome sequencing of E26 revealed a mutation in the open reading frame UGA2 which encodes for a succinate semialdehyde dehydrogenase involved in the $\gamma$-aminobutyric acid (GABA) assimilation pathway. They concluded that a decrease in GABA assimilation pathway could reduce the flux through the TCA cycle, thus redirecting more carbon towards the lipogenic pathway (Liu et al., 2015a).

\subsubsection{Modulating metabolic regulators expression}

The regulation of cellular metabolic regulators has been an effective strategy to facilitate lipid accumulation in Y. lipolytica. Studies have shown that SNF1 is a negative metabolic regulator of FAs accumulation. Seip et al. (2013) concluded that the deletion of SNF1 in Y. lipolytica induced an upregulation of the genes ACL1 and acetyl-CoA synthetase (ACS2) leading to an improved pool of acetyl-CoA and resulting in a 2.6-fold higher lipid content in mutants compared to wild-type strains (Seip et al., 2013). Other researchers combined the deletion of SNF1 regulator with the overexpression of DGA1 and DGA2 genes in Y. lipolytica, which resulted in a 2.47-fold increase in lipid content (Abghari and Chen, 2017). Similarly, the deletion of the glucose repression regulator MIG1 led to the upregulation of many genes associated to lipid synthesis and the downregulation of the MFE1 gene. As a result, the lipid content in Y. lipolytica improved from $36 \%$ to $48.7 \%$ and the biosynthesis of the FAs C18:1 increased from $45.1 \%$ to $60.2 \%$ (Wang et al., 2013). Liu et al. (2015b) studied the role of $\mathrm{mga} 2$ as a regulator of desaturase gene expression in $Y$. lipolytica. They showed that mutating or deleting the mga2 gene allowed the overexpression of $\Delta$-9-desaturase (OLE1) and resulted in the increase of the metabolism of unsaturated FAs (notably C16:1 and C18:1) (Liu et al., 2015b). Wang et al. (2018) evaluated the regulatory function of MHY1 gene in lipid synthesis. The deletion of this gene regulated the expression of 1567 genes involved in lipid biosynthesis in Y. lipolytica and increased lipid content from $30.2 \%$ (wild-type strain) to $43.1 \%$ ( $\Delta$ mhy1 strain) (Wang et al., 2018).

\subsubsection{Heterologous gene expression}

Several studies evaluated the expression of heterogeneous genes to improve lipid accumulation in Y. lipolytica. Yan et al. (2020) combined the overexpression of native genes (SCD, $\Delta-12$ desaturase $(\Delta-12 \mathrm{D}), \mathrm{ACC} 1, \mathrm{DGA} 1)$ and heterologous $\Delta-15$ desaturase $(\Delta-15 \mathrm{D})$ gene from flax with the deletion of the endogenous PEX10 and MFE1. The resulting strain showed a maximal lipid content of $77.8 \%$ with a lipid yield of $50 \mathrm{~g} / \mathrm{L}$ (Yan et al., 2020). Friedlander et al. (2016) applied similar modifications by overexpressing DGA1 and DGA2, respectively from Rhodosporidium toruloides and Claviceps purpurea, and deleting the endogenous TGL3 involved in lipid degradation, and demonstrated that these modifications resulted in a lipid yield of $85 \mathrm{~g} / \mathrm{L}$ (Friedlander et al., 2016). The overexpression of ACL gene involved in the production of acety-CoA from Mus musculus increased the lipid content in Y. lipolytica from $7.3 \%$ to $23 \%$ without a significant change in the FAs profile (Zhang et al., 2014). Moreover, the overexpression of Vitreoscilla haemoglobin in Y. lipolytica for improving $\mathrm{O}_{2}$ consumption during fermentation, increased the total FAs content by $40 \%$ compared to the wild-type strain when the dissolved oxygen concentration was measured at 30\% (Zhang et al., 2019a).

\subsubsection{Engineering alternative pathways}

\subsubsection{Alternative acetyl-CoA pathways}

In Y. lipolytica, the ACL provides acetyl-CoA from citrate when the TCA cycle is repressed under nitrogen depletion conditions. To decouple acetyl-CoA production from nitrogen depletion and increase the amount of acetyl-CoA, Xua et al. (2016) overexpressed the peroxisomal carnitine acetyltransferase (perCAT2) from $S$. cerevisiae and the endogenous genes (ACC1, DGA1). They observed an increase in lipid content and titer compared to the strain that only overexpressed ACC1 and DGA1 genes (Xua et al., 2016). In another study, Niehus et al. (2018) engineered a new strain of Y. lipolytica that can produce lipids using xylose as a carbon substrate. They overexpressed native xylitol dehydrogenase (XDH), xylose reductase (XR), and xylulose kinase (XK) in the Pold strain, to allow growth on xylose. They also designed two efficient pathways for the production of acetyl-CoA from xylulose-5-P. In the first pathway, they overexpressed phosphoketolase (XPKA) from Aspergillus nidulans that converts D-xylulose-5-P to acetyl-P and phosphotransacetylase (PTA) from Bacillus subtilis that changes acetyl-P to acetyl-CoA. In the second pathway, they overexpressed the XPKA and acetate kinase (ACK) enzymes from Aspergillus nidulans to obtain acetate 
S. E1 Kantar et al.: OCL 2021, 28, 51

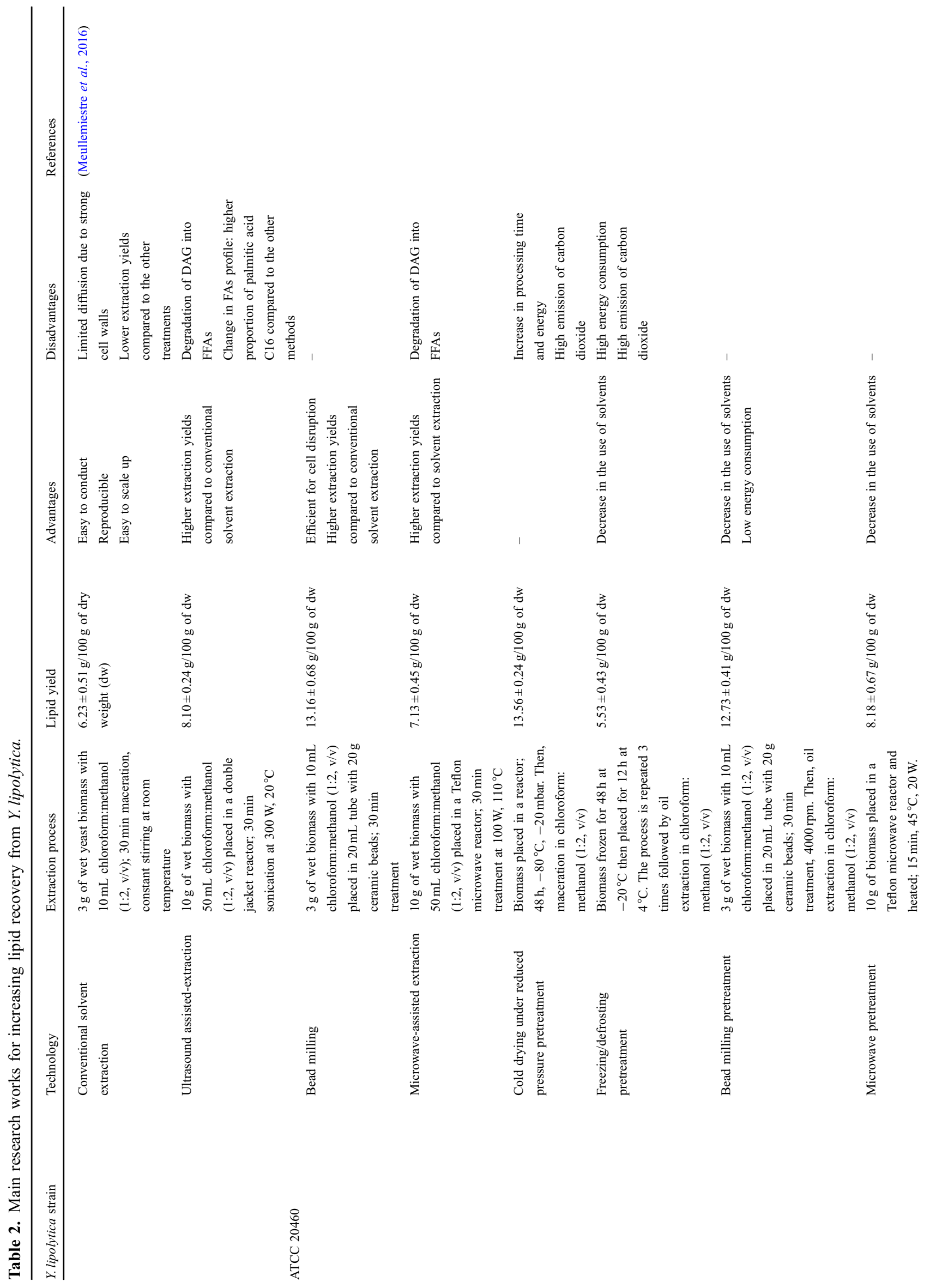


S. El Kantar et al.: OCL 2021, 28, 51

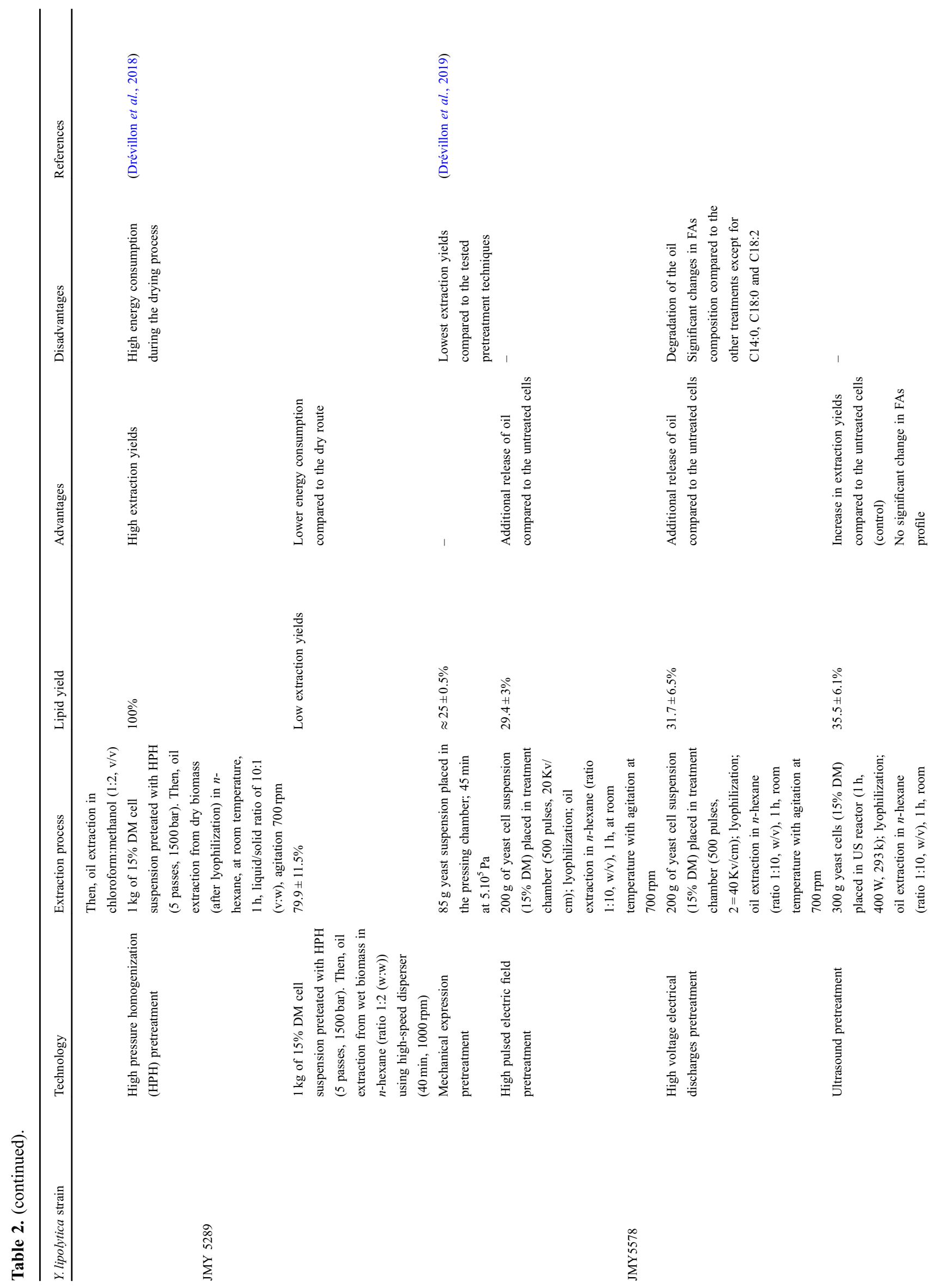

Page 9 of 19 
S. El Kantar et al.: OCL 2021, 28, 51

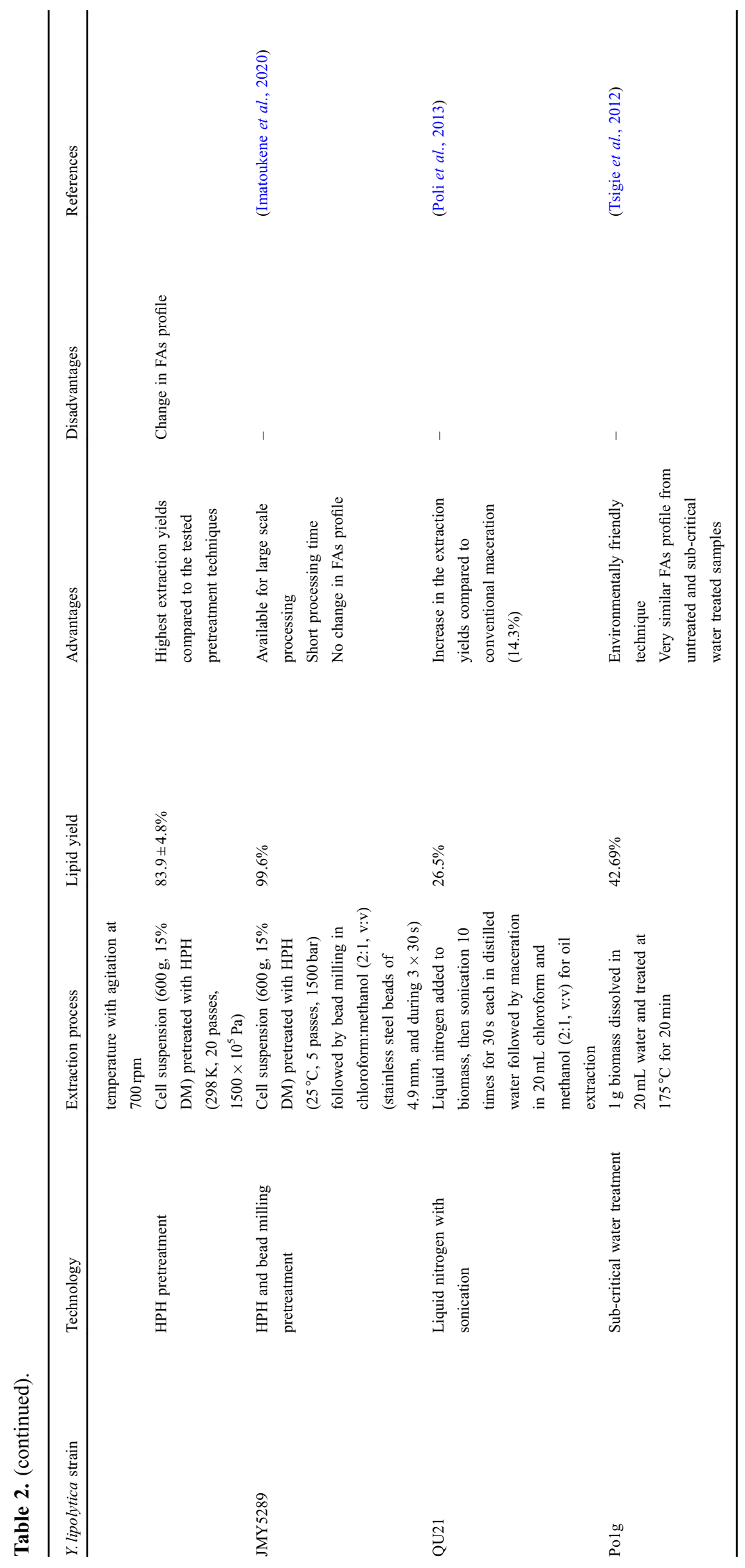

Page 10 of 19 
which is then converted to acetyl-CoA by the acetyl-CoA synthetase (ACS2) (Niehus et al., 2018). Similarly, Yook et al. (2020) introduced a xylose isomerase pathway in Y. lipolytica. They combined the overexpression of xylose isomerase gene XylA from $S$. cerevisiae and the endogenous XK and DGA1 genes with the deletion of PEX10 gene to prevent lipid degradation and improve lipid production from xylose substrate (Yook et al., 2020).

\subsubsection{Cytosolic NADPH pathways}

TAG synthesis involves large amounts of NADPH in both elongation step and desaturation reaction (Ratledge, 2014). Previous studies showed that malic enzyme (MAE) has a key role in providing NADPH in oleaginous yeasts and its overexpression resulted in a 2.5-fold increase in lipid content in both Mucor circinelloides and Mortierella alpine (Zhang et al., 2007). To understand the source of NADPH in Y. lipolytica during lipid accumulation, Wasylenko et al. (2015) used ${ }^{13} \mathrm{C}$-Metabolic Flux Analysis of a Y. lipolytica engineered strain that overexpresses ACC1 and DGA1 for a high lipid production from glucose substrate. The comparison of the flux between the wild-type and the engineered strains showed that the oxidative pentose phosphate pathway (oxPPP) is the main source of lipogenic NADPH in Y. lipolytica (Wasylenko et al., 2015). Qiao et al. (2017) adopted several strategies to increase NADPH supply in Y. lipolytica. They activated the pyruvate/oxaloacetate/malate cycle which can convert one molecule of NADH to NADPH (using 1 ATP) through the expression of the malic enzyme MCE2 from Mucor circinelloides. The highest lipid yield of $0.231 \mathrm{~g} / \mathrm{g}$ was obtained by overexpressing simultaneously the $\mathrm{NADP}^{+}$glyceraldhyde-3-phosphate dehydrogenase GapC from Clostridium acetobutylicum and the heterogeneous MCE2 (Qiao et al., 2017).

\subsubsection{Oxidative stress defense pathway}

Lipogenesis is generally initiated by nitrogen starvation which leads to a variety of cellular stress responses (Morin et al., 2011). The primary stress response is associated with the increased concentrations of reactive oxygen species (ROS) which results in lipids oxidation and peroxidation and the generation of reactive aldehydes (Li et al., 2011; Xu et al., 2017). Consequently, the elevated oxidative stress may result in the inactivation of the enzymes involved in lipid biosynthesis and the consumption of the stored lipids as an energy source to maintain cellular homeostasis (Grimsrud et al., 2008). Therefore, Xu et al. (2017) engineered an oxidative defense pathway to improve lipid production in Y. lipolytica. They overexpressed glutathione disulfide reductase (GSR), glutathione peroxidase (ylGPO), glucose-6-phosphate dehydrogenase (ScZwf) and aldehyde dehydrogenase (EcALDH) to resist reactive oxygen and aldehyde stress in Y.lipolytica. The engineered strain accumulated 2 times more lipids (82.5\%) compared to the wildtype strain (40.6\%) (Xu et al., 2017).

\subsection{Modifying the medium composition}

Multiple nutrients are essential for microbial growth and lipid production. Monosaccharides such as glucose, fructose, galactose, sucrose, pure glycerol and organic acids are usually used as carbon sources for yeast lipid production (Hapeta et al., 2017; Qin et al., 2017). Several studies investigated the efficiency of low-cost substrates such as industrial by-products or lignocellulosic biomass for effective lipid production in Y. lipolytica. Crude glycerol has many advantages including low cost, high availability and less $\mathrm{CO}_{2}$ emission during fermentation (Qin et al., 2017). Previous studies have shown the ability of Y. lipolytica to convert crude glycerol coming from industrial by-products into single cell oils (Cheirsilp and Louhasakul, 2013; Dobrowolski et al., 2016). Poli et al. (2014) observed no significant difference in lipid content when they replaced pure glycerol $(1.48 \mathrm{~g} / \mathrm{L})$ with crude glycerol $(1.27 \mathrm{~g} / \mathrm{L})$ in a medium containing ammonium sulfate as a nitrogen source (Poli et al., 2014). However, the presence of impurities in crude glycerol could negatively affect lipid production. Kumar et al. (2020) purified crude glycerol to use it as a carbon source for lipid production in Y.lipolytica. The cultures with purified glycerol presented higher lipid yields $(19.47 \mathrm{~g} / \mathrm{L})$ compared to the cultures with crude glycerol $(7.21 \mathrm{~g} / \mathrm{L})$. This difference in lipid content could be explained by the presence of high potassium concentration in crude glycerol that may inhibit the ACL enzyme responsible for the conversion of citrate into acetyl-CoA. The accumulated citrate is therefore secreted out of the cell rather than converted into lipids (Kumar et al., 2020). The addition of fat such as olive oil to crude glycerol improved lipid accumulation in Y. lipolytica due to lipase activation (Magdouli et al., 2017; Ayadi et al., 2018). Krzyczkowska and Kozłowska (2017) found that the addition of almond oil as a carbon source stimulated the activity of lipase enzyme, and resulted in the highest lipolytic activity after $48 \mathrm{~h}$ of culture (Krzyczkowska and Kozłowska, 2017). Louhasakul et al. (2020) highlighted the effect of adding biosurfactants to hydrophobic substrates on lipid productivity. Y. lipolytica cultivated in palm oil mill effluent with $2 \%$ crude glycerol produced 1.25-fold more lipids in the presence of biosurfactants (Louhasakul et al., 2020). Therefore, the addition of surfactants to the fermentation media containing hydrophobic substrates, may increase the permeability of the cell membranes, leading to more nutrients uptake (Taoka et al., 2011) and lipase secretion (Deive et al., 2009). Gao et al. (2017) evaluated the growth and lipid accumulation of Y. lipolytica cultured on volatile fatty acids (VFAs) such as butyric, propionic and acetic acids. Among the tested VFAs, the yeast showed a fastest consumption rate of acetate that could be directly cleaved into acetyl-CoA, unlike propionate and butyrate. The highest lipid yield coefficient $(0.290 \mathrm{~g} \mathrm{lipid} / \mathrm{g}$ dry cell weight) was obtained with an initial concentration of $2.5 \mathrm{~g} / \mathrm{L}$ of acetic acid at $\mathrm{pH} 6$ (Gao et al., 2017). In a further study, Gao et al. (2020) improved lipid accumulation in Y. lipolytica cultivated on VFAs. They obtained the highest lipid concentration of $10.11 \mathrm{~g} / \mathrm{L}$ from $70 \mathrm{~g} / \mathrm{L}$ of acetic acid under alkaline conditions (optimal pH 8) (Gao et al., 2020).

In addition to carbon, nitrogen is an essential component of fermentation media. Ammonium sulfate is generally used as a nitrogen source in the media for yeast fermentation. Brabender et al. (2018) conducted a study to evaluate the effect of synthetic urine $(18 \mathrm{~g} / \mathrm{L}$ urea) as an alternative low-cost nitrogen source for the accumulation of lipids in Y. lipolytica $\Delta$ pex10 strain. The cultures containing synthetic urine and glucose as a carbon source $(\mathrm{C}: \mathrm{N}=240: 1)$ accumulated 
approximately 2 times more lipids compared to cultures containing ammonium sulfate as a nitrogen source (Brabender et al., 2018). This study showed the possibility of using natural waste product such as human urine as a nitrogen source to improve lipid production in yeast.

Bellou et al. (2016) studied the effect of nutrients limitation on lipogenesis. When glycerol was used as a carbon source, lipid content in Y. lipolytica increased from $12.8 \%(\mathrm{w} / \mathrm{w})$ in the media with single nitrogen limitation to $23.5 \% \mathrm{w} / \mathrm{w}$ in the media with double nitrogen and magnesium limitation. A further improvement in lipid accumulation $(47.5 \%$, w/w) was observed when glycerol was replaced with glucose with double nitrogen and magnesium limitation (Bellou et al., 2016).

\subsection{Regulating the physicochemical parameters}

Changes in the cultivation parameters (e.g., $\mathrm{pH}$, aeration, temperature, etc.) are needed to determine the optimal conditions for lipid accumulation. Kuttiraja et al. (2018) showed the effect of $\mathrm{pH}$ controlling on lipid production in Y. lipolytica. They observed a $15 \%$ increase in lipid production when the $\mathrm{pH}$ was maintained at 6.5 in glycerol-based fermentation media compared to $\mathrm{pH}$-uncontrolled fermentation (Kuttiraja et al., 2018). In a separate study, Sekova et al. (2019) showed that a pH increase from 5.5 to 9 , caused a decrease in TAG level in Y. lipolytica respectively from $63 \%$ to $37 \%$ (Sekova et al., 2019). Studies have shown that the expression of genes involved in lipid synthesis was not $\mathrm{pH}$ dependent. However, some mitochondrial transporters are strongly expressed at $\mathrm{pH} 6$ which results in an increase in citric acid transport into the cytoplasm and its subsequent conversion to FAs (Zhang et al., 2019b). Lopes et al. (2018) highlighted the influence of oxygen transfer rate (OTR) factor on lipid production in Y. lipolytica, cultivated on glucose media. They observed a 1.6-fold improvement in lipid content when the OTR increased from $96 \mathrm{mg} / \mathrm{L} / \mathrm{h}$ to $192 \mathrm{mg} / \mathrm{L} / \mathrm{h}$ (Lopes et al., 2018). Previous studies showed that the increase in dissolved oxygen concentration in the fermentation media upregulates the activities of ACL and malic enzymes involved in lipid synthesis (Bellou et al., 2014). By contrast, other authors observed a decrease in lipid accumulation in Y. lipolytica cultivated in glycerol media, when the dissolved oxygen concentration increased from $30 \%$ to $40 \%$ (Magdouli et al., 2018). Similarly, Papanikolaou et al. (2002a) observed a remarkable growth of Y. lipolytica at an oxygen saturation of $60 \%$ but non-significant changes in lipid synthesis when the oxygen saturation varied between 5\% and 15\% (Papanikolaou et al., 2002a). The decrease in lipid accumulation in aerated cultures could be attributed to the increase in oil biodegradation (Martins et al., 2012; Magdouli et al., 2018). Therefore, it is important to find a suitable balance between oxygen needed for growth and lipid accumulation by the application of a two-stage cultivation strategy (Sara et al., 2016). Kavšcek et al. (2015) decreased the dissolved oxygen concentration from $50 \%$ to $1 \%$ after $20 \mathrm{~h}$ of fermentation, which resulted in a 25 -fold increase in lipid content in Y. lipolytica within $36 \mathrm{~h}$ (Kavšcek et al., 2015).

\subsection{Changing of the cultivation modes}

Different operational modes can be applied for the cultivation of Y. lipolytica for lipid production. The batch mode is the most studied method for lipid production in oleaginous yeasts and it can be performed either in flasks or in bioreactors (Carsanba et al., 2020). It consists of a closed system where the cells and substrates are provided at the beginning and the fermentation occurs without any external intervention (Karamerou and Webb, 2019). However, in batch fermentation, a high $\mathrm{C} / \mathrm{N}$ ratio is required which could lead to stressful conditions for yeast and result in the decrease of cell growth and lipid productivity (Christophe et al., 2012) . Therefore, fed-batch cultivation process has been applied to obtain high cell density and cellular lipid content in oleaginous yeasts. In the fed-batch cultivation, initial substrate inhibition can be avoided since nutrients are added intermittently or continuously to the culture vessel during fermentation (Poontawee and Limtong, 2020). The fed-batch fermentation using glucose and olive oil as substrates led to a 3-fold improvement in lipase production by $Y$. lipolytica compared to batch fermentation (Fickers et al., 2009). A two-stage fedbatch cultivation has also been applied for lipid production by Y. lipolytica. In a first stage, the cultivation of cells in a nutrient-rich medium resulted in a high cell concentration. Then, in a second stage, the addition of carbon source without auxiliary nutrients increased lipid productivity. A two-stage fed-batch cultivation of Y. lipolytica using glycerol and VFAs as carbon sources, resulted in a significant increase in lipid yields compared to batch fermentation with one carbon source (Fontanille et al., 2012). Moreover, Wang et al. (2019) applied a two-stage fed-batch fermentation using pretreated cane molasses as a carbon source for lipid production in Y. lipolytica. The fermentation process resulted in a lipid level of $12.2 \mathrm{~g} / \mathrm{L}$ which is higher than that obtained at batch flask level (7.2 g/L) (Wang et al., 2019). Continuous fermentation has also been effective to increase lipid productivity in Y. lipolytica. In continuous operation, cultures are continuously supplied with substrates and the fermentation broth is withdrawn at the same rate to keep the volume constant in the fermentation system. Therefore, the $\mathrm{C} / \mathrm{N}$ ratio could be maintained constant in the steady state and lipid accumulation would only depend on the dilution rate (Rakicka et al., 2015). The effect of dilution rates on lipid synthesis by Y. lipolytica in continuous fermentation process was evaluated and the highest lipid content was obtained at a low dilution rate of $0.03 \mathrm{~h}^{-1}$ (Papanikolaou et al., 2002a; Papanikolaou and Aggelis, 2002). Rakicka et al. (2015) found that the continuous fermentation process was more effective than the batch-fermentation for lipid synthesis in Y. lipolytica. The yeast produced $24.2 \mathrm{~g} / \mathrm{L}$ of lipids in continuous cultures when the dilution rate was maintained at $0.01 \mathrm{~h}^{-1}$ compared to $22.6 \mathrm{~g} / \mathrm{L}$ in the fed-batch cultivation process (Rakicka et al., 2015).

\subsection{In silico modeling}

New strains of Y. lipolytica with high lipid accumulation have been engineered using in silico modeling. Wei et al. (2017) have developed a genome scale metabolic model (GEM) of Y. lipolytica to predict metabolic engineering strategies that improve lipid accumulation. The simulation of overexpressing 6 genes enhanced the availability of acetylCoA and malonyl-CoA and resulted in a $34.1 \%$ improvement of TAG production. Further simulation predicted that the 
addition of L-threonine or L-aspartate amino acids could lead to a 55.5\% improvement in TAG synthesis rate (Wei et al., 2017). Kim et al. (2019) also used a computational method to predict the overexpression or knockout targets on lipid accumulation in Y. lipolytica. One of the knockout targets implicated in one-carbon/methionine metabolism has been reconstructed and showed a $45 \%$ increase in lipid accumulation compared to the wild-type strain (Kim et al., 2019). GEM was also used to predict the effect of nitrogen and oxygen depletion on lipid accumulation in Y. lipolytica. The model was validated experimentally using fed-batch fermentation (Kavšcek et al., 2015). Therefore, GEMs are powerful tools to understand and predict the effects of genetic modifications or cultivation conditions on lipid accumulation in Y. lipolytica.

\section{Enhancing lipid extraction from Y. lipolytica}

Chloroform and methanol mixtures are commonly used to extract lipids from oleaginous yeasts according to the conventional Bligh and Dyer and the Folch methods (Breil et al., 2017). The efficiency of Folch method for lipid extraction depends on the yeast strain. For example, Folch method was efficient for lipid extraction from Y. lipolytica (Sarantou et al., 2021) while an acid digestion method $(2.5 \mathrm{M}$, $100{ }^{\circ} \mathrm{C}, 30 \mathrm{~min}$ ) was required prior to Folch method for lipid recovery from Lipomyces starkeyi (Tchakouteu et al., 2015). However, Y. lipolytica cell wall is characterized by a high chitin content ( $7 \%$ of wall mass) which is responsible to the strength and resistance of the wall and could limit the extraction of intracellular lipids (Khot et al., 2020). Therefore, after fermentation, the alteration of cell-wall permeability is required to improve and facilitate lipid extraction. For this purpose, several cell disruption technologies were investigated such as bead milling, high-pressure homogenization, ultrasound and microwave to intensify lipid extraction from Y. lipolytica (Tab. 2).

\subsection{Bead milling}

Bead milling is an efficient mechanical cell disruption method characterized by its high potential for industrial implementation. Generally, a bead miller involves a motordriven central shaft that may carry different designs of agitators (e.g., concentric or eccentric disks) inside a grinding chamber filled with glass or ceramic beads. During the operation, the movement of the beads causes compaction, shear forces and energy transfer to the cells, which results in cell disruption such as grinding (Günerken et al., 2015). Meullemiestre et al. (2016) compared bead milling (4000 rpm, $25^{\circ} \mathrm{C}$ ) to other technologies such as microwave (20 bar, $\left.110^{\circ} \mathrm{C}\right)$ and ultrasound $\left(300 \mathrm{~W}, 25^{\circ} \mathrm{C}\right)$ for the extraction of lipids from $Y$. lipolytica. Results have shown that bead milling was the most efficient cell disruption technique and increased the extracted lipid yields by two times compared to the conventional maceration in methanol-chloroform $(2: 1, \mathrm{v} / \mathrm{v})$ (constant stirring, $25^{\circ} \mathrm{C}$ ) (Meullemiestre et al., 2016).

\subsection{High-pressure homogenization}

High pressure homogenization (HPH) is a second mechanical process that aims to push a suspension to pass through a narrow gap at high pressures. During its passage, the suspension is subjected to multiple phenomena such as friction, cavitation and turbulence which results in obtaining a fine homogenate (Tribst et al., 2008). This technique was efficient for the recovery of lipids from algae (Yap et al., 2015) and from the oleaginous yeast Cryptococcus curvatus (Thiru et al., 2011). Drévillon et al. (2018) investigated the efficiency of $\mathrm{HPH}$ pre-treatment prior to high-speed maceration in $n$-hexane for the recovery of lipids from Y. lipolytica. They found the optimal HPH parameters of 5 passes and 1500 bar yielded a $100 \%$ recovery of lipids in dry route and $80 \%$ in wet route (Drévillon et al., 2018). In another study, the authors evaluated different cell disruption techniques prior to maceration in $n$-hexane for oil recovery from Y. lipolytica. Among mechanical expression (ME), moderate pulsed electric field assisted mechanical expression (MPEF-ME), high pulsed electric fields (HPEF), high voltage electrical discharges (HVED), ultrasound (US), and HPH pre-treatment techniques, $\mathrm{HPH}$ was the most efficient technique and allowed the extraction of $83.8 \pm 4.8 \%$ of oil compared to $19.8 \pm 0.5 \%$ with maceration in $n$-hexane without any pre-treatment (Drévillon et al., 2019). Imatoukene et al. (2020) combined HPH with bead milling pretreatment and evaluated the efficiency of several solvents for lipid recovery from Y.lipolytica. The highest lipid yield (99.6\%) was obtained when bead milling was preceded by HPH and the oil extraction was performed in chloroform:methanol. Among the tested green solvents, isoamyl acetate allowed the extraction of $96.7 \%$ of lipids from pretreated biomass (Imatoukene et al., 2020).

\subsection{Ultrasound}

Ultrasound technology is one of the most widely used method to disrupt the cell wall of oleaginous microorganisms (Patel et al., 2018). It is a physical treatment based on the cavitation phenomenon. During the propagation of ultrasound waves in a liquid media, expansion (low pressure) and compression (high pressure) cycles are induced, involving the formation of cavitation bubbles, their growth and their implosion when their size reaches a critical value. The collapse of cavitation bubbles induces a local increase in temperature and pressure, respectively, up to around $5000 \mathrm{~K}$ and 50 to $1000 \mathrm{~atm}$, which causes cell membrane disruption (Chemat et al., 2017). Previous studies evaluated the effect of ultrasound on the intensification of lipid extraction from oleaginous yeasts (Kumar et al., 2020) and microalgae (Araujo et al., 2013). Few reports are available on the extraction of lipids from Y. lipolytica using ultrasound treatment. Poli et al. (2013) studied the effect of sonication on the disruption of Y. lipolytica cell walls. The experiment consisted on adding liquid nitrogen to biomass followed by sonication 10 times for $30 \mathrm{~s}$ each, in a mixture of chloroform-methanol. Compared to dry maceration in chloroform-methanol which yielded $14.3 \%$ of oil, ultrasound extraction technique allowed an increase in oil recovery up to $26.5 \%$ (Poli et al., 2013). 


\subsection{Microwave}

Microwave treatment was also used to enhance lipid extraction from oleaginous yeasts. Microwaves are electromagnetic radiations with a frequency ranging from 0.3 to $300 \mathrm{GHz}$. The energy produced during microwave treatment provokes a rapid and homogeneous heating of the solvent and the suspension, by dipole rotation and ionic conduction (Bouras et al., 2015). The cell disruption induced by microwave treatment increased the extraction rates of lipids from $S$. cerevisiae compared to the conventional maceration in methanol-chloroform (Khoomrung et al., 2013). Microwave treatment combined to acid-catalyzed transesterification was also efficient to extract and modify lipids from Rhodotorula glutinis in $30 \mathrm{~s}$ at $120^{\circ} \mathrm{C}$ compared to $4 \mathrm{~h}$ by Soxhlet solvent extraction (Chuck et al., 2014). However, in the case of Y. lipolytica, the treatment of the biomass with microwaves $\left(1000 \mathrm{~W}, 110^{\circ} \mathrm{C}\right)$ slightly increased lipid yield to $7.13 \mathrm{~g} / 100 \mathrm{~g}$ of DW compared to $6.53 \mathrm{~g} / 100 \mathrm{~g}$ of DW with the conventional maceration in methanol-chloroform $(2: 1, \mathrm{v} / \mathrm{v})$. The obtained result was attributed to the degradation of lipids during microwave-assisted extraction. To improve cell disruption by microwaves and avoid lipid degradation, the authors tested microwave pretreatment of biomass during $15 \mathrm{~min}$ at a power of $20 \mathrm{~W}$ and a constant temperature of $45^{\circ} \mathrm{C}$ followed by two washing steps in chloroform:methanol $(1: 2, \mathrm{v} / \mathrm{v})$ at room temperature. In these conditions, lipids recovery increased to $8.18 \pm 0.67 \mathrm{~g} / 100 \mathrm{~g}$ of DW (Meullemiestre et al., 2016). In the same study, cold drying $\left(-80^{\circ} \mathrm{C},-20 \mathrm{mbar}, 48 \mathrm{~h}\right)$, freezing/ defrosting $\left(-20^{\circ} \mathrm{C}, 24 \mathrm{~h} / 4^{\circ} \mathrm{C}, 12 \mathrm{~h}\right)$ and bead milling (4000 rpm, $30 \mathrm{~min}$ ) were also tested as pretreatment techniques to improve lipids recovery from Y. lipolytica. The maximum lipid yield of $13.56 \mathrm{~g} / 100 \mathrm{~g}$ of DW was obtained when cold drying under pressure was applied prior to the maceration step (Meullemiestre et al., 2016).

\subsection{Sub-critical water}

Sub-critical water (SCW) treatment was also efficient for the recovery of lipids from Y. lipolytica (Tsigie et al., 2012; Tran Nguyen et al., 2013). It consists of using water as a solvent at high temperatures (between $100^{\circ} \mathrm{C}$ and $374^{\circ} \mathrm{C}$ ) under high pressure to keep water in the liquid state. Under these conditions, the dielectric constant of water decreases which improves the extraction of hydrophobic compounds without using organic solvents (Shitu et al., 2015). In a first study, Tsigie et al. (2012) applied SCW on Y. lipolytica biomass as a pretreatment step prior to maceration in a mixture of hexane:methanol $(2: 1, \mathrm{v} / \mathrm{v})$ for $4 \mathrm{~h}$. The amount of extracted neutral lipids increased from $23.21 \% \mathrm{w} / \mathrm{w}$ for untreated biomass to $42.69 \% \mathrm{w} / \mathrm{w}$ when the biomass was pretreated at $175^{\circ} \mathrm{C}$ using $20 \mathrm{~mL}$ water for $20 \mathrm{~min}$ (Tsigie et al., 2012). In another study, the pretreatment of Y. lipolytica biomass with SCW for $15 \mathrm{~min}$ at $175^{\circ} \mathrm{C}$ caused cell walls' rupture and resulted in 10 times increase in the extractable neutral lipids compared to the untreated biomass (Tran Nguyen et al., 2013).

Further cell disruption technologies for oil recovery from oleaginous microorganisms were developed by Koubaa et al. (2020). However, to date, there is no study regarding the membrane-based purification techniques of oil extracted from oleaginous yeasts including Y. lipolytica.

\section{Conclusions}

Single cell oils produced by oleaginous microorganisms are considered as potential alternatives to plant and animal oil for biodiesel production. The yeast Y. lipolytica presents a promising host for biodiesel production, due to its ability to accumulate high amounts of intracellular lipids under some cultivation conditions. The first crucial point for the commercial utilization of microbial lipids is the cost-effective production that depends on the yeast strain and the fermentation conditions. This review summarized the approaches that have been used to improve lipid production in Y. lipolytica. Higher lipid productivity in Y. lipolytica is achieved through metabolic engineering strategies including the regulation of endogenous genes and metabolic regulators, the expression of heterogeneous genes and the design and construction of alternative pathways. High lipid yields can also be obtained by using low-cost effective carbon and nitrogen sources and modifying fermentation conditions such as $\mathrm{pH}$, temperature, aeration and cultivation mode. After the fermentation step, lipid extraction from biomass is a major issue that needs to be dealt with to improve the recovery yields. For this purpose, this review discussed the cell disruption technologies that have been used to optimize the recovery of lipids from Y. lipolytica.

\section{Conflict of interest}

The authors declare no conflict of interest.

Acknowledgements. This work was performed within the project YaLiOl supported by the ANR grant "ANR-20CE43-0007" of the French National Research Agency (ANR) in France.

\section{References}

Abghari A, Chen S. 2014. Yarrowia lipolytica as an oleaginous cell factory platform for production of fatty acid-based biofuel and bioproducts. Front Energy Res 2: 1-21. https://doi.org/10.3389/ fenrg.2014.00021.

Abghari A, Chen S. 2017. Engineering Yarrowia lipolytica for enhanced production of lipid and citric acid. Fermentation 3(3). https://doi.org/10.3390/fermentation3030034.

Abghari A, Madzak C, Chen S. 2017.Combinatorial engineering of Yarrowia lipolytica as a promising cell biorefinery platform for the de novo production of multi-purpose long chain dicarboxylic acids. Fermentation 3(3). https://doi.org/10.3390/fermenta tion3030040.

Ali N, Zhang Q, Liu ZY, Li FL, Lu M, Fang XC. 2020. Emerging technologies for the pretreatment of lignocellulosic materials for bio-based products. Appl Microbiol Biotechnol 104(2): 455-473. https://doi.org/10.1007/s00253-019-10158-w.

Amalia L, Zhang YH, Ju YH, Tsai SL. 2020. Enhanced lipid production in Yarrowia lipolytica Polg by over-expressing lro1 gene under two different promoters. Appl Biochem Biotechnol 191(1): 104-111. https://doi.org/10.1007/s12010-020-03226-9. 
Araujo GS, Matos LJBL, Fernandes JO, et al. 2013. Extraction of lipids from microalgae by ultrasound application: Prospection of the optimal extraction method. Ultrason Sonochem 20(1): 95-98. https://doi.org/10.1016/j.ultsonch.2012.07.027.

Athenstaedt K, Jolivet P, Boulard C, et al. 2006. Lipid particle composition of the yeast Yarrowia lipolytica depends on the carbon source. Proteomics 6(5): 1450-1459. https://doi.org/ 10.1002/pmic. 200500339.

Ayadi I, Belghith H, Gargouri A, Guerfali M. 2018. Screening of new oleaginous yeasts for single cell oil production, hydrolytic potential exploitation and agro-industrial by-products valorization. In: Process Safety and Environmental Protection, Vol. 119. Institution of Chemical Engineers. https://doi.org/10.1016/j. psep.2018.07.012.

Bellou S, Makri A, Triantaphyllidou IE, Papanikolaou S, Aggelis G. 2014. Morphological and metabolic shifts of Yarrowia lipolytica induced by alteration of the dissolved oxygen concentration in the growth environment. Microbiology (United Kingdom) 160(Part 4): 807-817. https://doi.org/10.1099/mic.0.074302-0.

Bellou S, Triantaphyllidou IE, Mizerakis P, Aggelis G. 2016. High lipid accumulation in Yarrowia lipolytica cultivated under double limitation of nitrogen and magnesium. J Biotechnol 234: 116126. https://doi.org/10.1016/j.jbiotec.2016.08.001.

Beopoulos A, Mrozova Z, Thevenieau F, et al. 2008. Control of lipid accumulation in the yeast Yarrowia lipolytica. Appl Environ Microbiol 74(24): 7779-7789. https://doi.org/10.1128/ AEM01412-08.

Bhutada G, Kavšček M, Ledesma-Amaro R, et al. 2017. Sugar versus fat: Elimination of glycogen storage improves lipid accumulation in Yarrowia lipolytica. FEMS Yeast Res 17(3): 1-10. https://doi. org/10.1093/femsyr/fox020.

Blazeck J, Hill A, Liu L, et al. 2014. Harnessing Yarrowia lipolytica lipogenesis to create a platform for lipid and biofuel production. Nat Commun 5: 1-10. https://doi.org/10.1038/ncomms4131.

Bouras M, Chadni M, Barba FJ, Grimi N, Bals O, Vorobiev E. 2015. Optimization of microwave-assisted extraction of polyphenols from Quercus bark. Ind Crops Prod 77: 590-601. https://doi.org/ 10.1016/j.indcrop.2015.09.018.

Brabender M, Hussain MS, Rodriguez G, Blenner MA. 2018. Urea and urine are a viable and cost-effective nitrogen source for Yarrowia lipolytica biomass and lipid accumulation. Appl Microbiol Biotechnol 102(5): 2313-2322. https://doi.org/ 10.1007/s00253-018-8769-z.

Breil C, Abert Vian M, Zemb T, Kunz W, Chemat F. 2017. "Bligh and Dyer" and Folch methods for solid-liquid-liquid extraction of lipids from microorganisms. Comprehension of solvatation mechanisms and towards substitution with alternative solvents. Int J Mol Sci 18(4): 1-21. https://doi.org/10.3390/ijms18040708.

Carsanba E, Papanikolaou S, Erten H. 2018. Production of oils and fats by oleaginous microorganisms with an emphasis given to the potential of the nonconventional yeast Yarrowia lipolytica. Crit Rev Biotechnol 38(8): 1230-1243. https://doi.org/10.1080/ 07388551.2018.1472065.

Carsanba E, Papanikolaou S, Fickers P, Erten H. 2020. Lipids by Yarrowia lipolytica strains cultivated on glucose in batch cultures. Microorganisms 8(7): 1-14. https://doi.org/10.3390/microorgan isms8071054.

Cheirsilp B, Louhasakul Y. 2013. Industrial wastes as a promising renewable source for production of microbial lipid and direct transesterification of the lipid into biodiesel. Bioresour Technol 142: 329-337. https://doi.org/10.1016/j.biortech.2013.05.012.

Chemat F, Rombaut N, Sicaire AG, Meullemiestre A, Fabiano-Tixier AS, Abert-Vian M. 2017. Ultrasound assisted extraction of food and natural products. Mechanisms, techniques, combinations, protocols and applications. A review. Ultrason Sonochem 34: 540-560. https://doi.org/10.1016/j.ultsonch.2016.06.035.

Christophe G, Kumar V, Nouaille R, et al. 2012. Recent developments in microbial oils production: A possible alternative to vegetable oils for biodiesel without competition with human food? Braz Arch Biol Technol 55(1): 29-46. https://doi.org/10.1590/ S1516-89132012000100004.

Chuck CJ, Lou-Hing D, Dean R, Sargeant LA, Scott RJ, Jenkins RW. 2014. Simultaneous microwave extraction and synthesis of fatty acid methyl ester from the oleaginous yeast Rhodotorula glutinis. Energy 69: 446-454. https://doi.org/10.1016/j.ener gy.2014.03.036.

Darvishi F, Fathi Z, Ariana M, Moradi H. 2017. Yarrowia lipolytica as a workhorse for biofuel production. Biochem Eng J 127: 87-96. https://doi.org/10.1016/j.bej.2017.08.013.

Datta A, Hossain A, Sanjay R. 2019. Asian J Chem 31(8): 1851-1858.

Deive FJ, Carvalho E, Pastrana L, Rúa ML, Longo MA, Sanroman MA. 2009. Strategies for improving extracellular lipolytic enzyme production by Thermus thermophilus HB27. Bioresour Technol 100(14): 3630-3637. https://doi.org/10.1016/j.bio rtech.2009.02.053.

Dobrowolski A, Mituła P, Rymowicz W, Mirończuk AM. 2016. Efficient conversion of crude glycerol from various industrial wastes into single cell oil by yeast Yarrowia lipolytica. Bioresour Technol 207: 237-243. https://doi.org/10.1016/j.bio rtech.2016.02.039.

Donot F, Fontana A, Baccou JC, Strub C, Schorr-Galindo S. 2014. Single cell oils (SCOs) from oleaginous yeasts and moulds: Production and genetics. Biomass Bioenergy 68(04): 135-150. https://doi.org/10.1016/j.biombioe.2014.06.016.

Drévillon L, Koubaa M, Vorobiev E. 2018. Lipid extraction from Yarrowia lipolytica biomass using high-pressure homogenization. Biomass Bioenergy 115: 143-150. https://doi.org/10.1016/j. biombioe.2018.04.014.

Drévillon L, Koubaa M, Nicaud JM, Vorobiev E. 2019. Cell disruption pre-treatments towards an effective recovery of oil from Yarrowia lipolytica oleaginous yeast. Biomass Bioenergy 128: 105320. https://doi.org/10.1016/j.biombioe.2019.105320.

Dulermo T, Nicaud JM. 2011. Involvement of the G3P shuttle and Boxidation pathway in the control of TAG synthesis and lipid accumulation in Yarrowia lipolytica. Metab Eng 13(5): 482-491. https://doi.org/10.1016/j.ymben.2011.05.002.

Dulermo T, Tréton B, Beopoulos A, Gnankon APK, Haddouche R, Nicaud JM. 2013. Characterization of the two intracellular lipases of Y. lipolytica encoded by TGL3 and TGL4 genes: New insights into the role of intracellular lipases and lipid body organisation. Biochim Biophys Acta-Mol Cell Biol Lipids 1831(9): 14861495. https://doi.org/10.1016/j.bbalip.2013.07.001.

Dulermo R, Gamboa-Meléndez H, Dulermo T, Thevenieau F, Nicaud JM. 2014. The fatty acid transport protein Fatlp is involved in the export of fatty acids from lipid bodies in Yarrowia lipolytica. FEMS Yeast Res 14(6): 883-896. https://doi.org/10.1111/ 1567-1364.12177.

Enamala MK, Enamala S, Chavali M, et al. 2018. Production of biofuels from microalgae $-\mathrm{A}$ review on cultivation, harvesting, lipid extraction, and numerous applications of microalgae. Renew Sustain Energy Rev 94: 49-68. https://doi.org/10.1016/j. rser.2018.05.012.

Fabiszewska AU, Zieniuk B, Kozłowska M, et al. 2021. Studies on upgradation of waste fish oil to lipid-rich yeast biomass in Yarrowia lipolytica batch cultures. Foods 10(2): 1-15. https://doi. org/10.3390/foods10020436. 
Fickers P, Destain J, Thonart P. 2009. Improvement of Yarrowia lipolytica lipase production by fed-batch fermentation. $J$ Basic Microbiol 49(2): 212-215. https://doi.org/10.1002/ jobm.200800186.

Fontanille P, Kumar V, Christophe G, Nouaille R, Larroche C. 2012. Bioconversion of volatile fatty acids into lipids by the oleaginous yeast Yarrowia lipolytica. Bioresour Technol 114: 443-449. https://doi.org/10.1016/j.biortech.2012.02.091.

Friedlander J, Tsakraklides V, Kamineni A, et al. 2016. Engineering of a high lipid producing Yarrowia lipolytica strain. Biotechnol Biofuels 9(1): 1-12. https://doi.org/10.1186/s13068-016-0492-3.

Fukuda R. 2013. Metabolism of hydrophobic carbon sources and regulation of it in n-alkane-assimilating yeast Yarrowia lipolytica. Biosci Biotechnol Biochem 77(6): 1149-1154. https://doi.org/ 10.1271/bbb.130164

Gálvez-López D, Chávez-Meléndez B, Vázquez-Ovando A, RosasQuijano R. 2019. The metabolism and genetic regulation of lipids in the oleaginous yeast Yarrowia lipolytica. Braz J Microbiol 50 (1): 23-31. https://doi.org/10.1007/s42770-018-0004-7.

Gao R, Li Z, Zhou X, Cheng S, Zheng L. 2017. Oleaginous yeast Yarrowia lipolytica culture with synthetic and food waste-derived volatile fatty acids for lipid production. Biotechnol Biofuels 10(1): 1-15. https://doi.org/10.1186/s13068-017-0942-6.

Gao R, Li Z, Zhou X, Bao W, Cheng S, Zheng L. 2020. Enhanced lipid production by Yarrowia lipolytica cultured with synthetic and waste-derived high-content volatile fatty acids under alkaline conditions. Biotechnol Biofuels 13(1): 1-16. https://doi.org/ 10.1186/s13068-019-1645-y.

Ghogare R, Chen S, Xiong X. 2020. Metabolic engineering of oleaginous yeast Yarrowia lipolytica for overproduction of fatty acids. Front Microbiol 11. https://doi.org/10.3389/ fmicb.2020.01717.

Gimpel JA, Henríquez V, Mayfield SP. 2015. In metabolic engineering of eukaryotic microalgae: Potential and challenges come with great diversity. Front Microbiol 6: 1-14. https://doi. org/10.3389/fmicb.2015.01376.

Grimsrud PA, Xie H, Griffin TJ, Bernlohr DA. 2008. Oxidative stress and covalent modification of protein with bioactive aldehydes. J Biol Chem 283(32): 21837-21841. https://doi.org/10.1074/jbc. R700019200.

Günerken E, D’Hondt E, Eppink MHM, Garcia-Gonzalez L, Elst K, Wijffels RH. 2015. Cell disruption for microalgae biorefineries. Biotechnol Adv 33(2): 243-260. https://doi.org/10.1016/j.biote chadv.2015.01.008.

Hapeta P, Rakicka M, Dulermo R, et al. 2017. Transforming sugars into fat-lipid biosynthesis using different sugars in Yarrowia lipolytica. Yeast 34(7): 293-304. https://doi.org/10.1002/ yea.3232.

Harzevili FD. 2014. Biotechnological applications of the Yeast Yarrowia lipolytica. Springer International Publishing, pp. 1-16. https://doi.org/10.1007/978-3-319-06437-6.

Imatoukene N, Koubaa M, Perdrix E, Benali M, Vorobiev E. 2020. Combination of cell disruption technologies for lipid recovery from dry and wet biomass of Yarrowia lipolytica and using green solvents. Process Biochem 90: 139-147. https://doi.org/10.1016/ j.procbio.2019.11.011.

Jeevan Kumar SP, Banerjee R. 2019. Enhanced lipid extraction from oleaginous yeast biomass using ultrasound assisted extraction: A greener and scalable process. Ultrason Sonochem 52: 25-32. https://doi.org/10.1016/j.ultsonch.2018.08.003.

Karamerou EE, Webb C. 2019. Cultivation modes for microbial oil production using oleaginous yeasts-A review. Biochem Eng J 151: 107322. https://doi.org/10.1016/j.bej.2019.107322.
Kavšcek M, Bhutada G, Madl T, Natter K. 2015. Optimization of lipid production with a genome-scale model of Yarrowia lipolytica. BMC Syst Biol 9(1): 1-13. https://doi.org/10.1186/ s12918-015-0217-4.

Khoomrung S, Chumnanpuen P, Jansa-Ard S, et al. 2013. Rapid quantification of yeast lipid using microwave-assisted total lipid extraction and HPLC-CAD. Anal Chem 85(10): 4912-4919. https://doi.org/10.1021/ac3032405.

Khot M, Raut G, Ghosh D, Alarcón-Vivero M, Contreras D, Ravikumar A. 2020. Lipid recovery from oleaginous yeasts: Perspectives and challenges for industrial applications. Fuel 259: 116292. https://doi.org/10.1016/j.fuel.2019.116292.

Kim M, Park BG, Kim EJ, Kim J, Kim BG. 2019. In silico identification of metabolic engineering strategies for improved lipid production in Yarrowia lipolytica by genome-scale metabolic modeling. Biotechnol Biofuels 12(1): 1-14. https:// doi.org/10.1186/s13068-019-1518-4.

Koubaa M, Imatoukene N, Drévillon L, Vorobiev E. 2020. Current insights in yeast cell disruption technologies for oil recovery: A review. Chem Eng Process-Process Intensif 150: 107868. https://doi.org/10.1016/j.cep.2020.107868.

Koutinas AA, Chatzifragkou A, Kopsahelis N, Papanikolaou S, Kookos IK. 2014. Design and techno-economic evaluation of microbial oil production as a renewable resource for biodiesel and oleochemical production. Fuel 116: 566-577. https://doi.org/ 10.1016/j.fuel.2013.08.045.

Krzyczkowska J, Kozłowska M. 2017. Effect of oils extracted from plant seeds on the growth and lipolytic activity of Yarrowia lipolytica yeast. JAOCS-J Am Oil Chem Soc 94(5): 661-671. https://doi.org/10.1007/s11746-017-2975-1.

Kumar LR, Yellapu SK, Tyagi RD, Drogui P. 2020. Purified crude glycerol by acid treatment allows to improve lipid productivity by Yarrowia lipolytica S KY7. Process Biochem 96: 165-173. https://doi.org/10.1016/j.procbio.2020.06.010.

Kuttiraja M, Dhouha A, Tyagi RD. 2018. Harnessing the Effect of $\mathrm{pH}$ on Lipid Production in Batch Cultures of Yarrowia lipolytica SKY7. Appl Biochem Biotechnol 184(4): 1332-1346. https://doi. org/10.1007/s12010-017-2617-y.

Lazar Z, Liu N, Stephanopoulos G. 2018. Holistic approaches in lipid production by Yarrowia lipolytica. Trends Biotechnol 36(11): 1157-1170. https://doi.org/10.1016/j.tibtech.2018.06.007.

Ledesma-Amaro R, Dulermo T, Nicaud JM. 2015. Engineering Yarrowia lipolytica to produce biodiesel from raw starch. Biotechnol Biofuels 8 (1): 1-12. https://doi.org/10.1186/s13068-015-0335-7.

Ledesma-Amaro R, Dulermo R, Niehus X, Nicaud JM. 2016. Combining metabolic engineering and process optimization to improve production and secretion of fatty acids. Metab Eng 38: 38-46. https://doi.org/10.1016/j.ymben.2016.06.004.

Li Y, Horsman M, Wu N, Lan CQ, Dubois-Calero N. 2008. Biofuels from microalgae. Biotechnol Progress 24(4): 815-820. https:// doi.org/10.1021/bp.070371k.

Li Q, Bai Z, O’Donnell A, Harvey LM, Hoskisson PA, McNeil B. 2011. Oxidative stress in fungal fermentation processes: The roles of alternative respiration. Biotechnol Lett 33(3): 457-467. https:// doi.org/10.1007/s10529-010-0471-x.

Liu L, Pan A, Spofford C, Zhou N, Alper HS. 2015a. An evolutionary metabolic engineering approach for enhancing lipogenesis in Yarrowia lipolytica. Metab Eng 29: 36-45. https://doi.org/ 10.1016/j.ymben.2015.02.003.

Liu L, Markham K, Blazeck J, et al. 2015b. Surveying the lipogenesis landscape in Yarrowia lipolytica through understanding the function of a Mga2p regulatory protein mutant. Metab Eng 31: 102-111. https://doi.org/10.1016/j.ymben.2015.07.004. 
Lopes M, Gomes AS, Silva CM, Belo I. 2018. Microbial lipids and added value metabolites production by Yarrowia lipolytica from pork lard. J Biotechnol 265: 76-85. https://doi.org/10.1016/j. jbiotec.2017.11.007.

Lopes M, Miranda SM, Alves JM, Pereira AS, Belo I. 2019. Waste cooking oils as feedstock for lipase and lipid-rich biomass production. Eur J Lipid Sci Technol 121(1): 1-9. https://doi.org/ 10.1002/ejlt.201800188.

Louhasakul Y, Cheirsilp B, Intasit R, Maneerat S, Saimmai A. 2020. Enhanced valorization of industrial wastes for biodiesel feedstocks and biocatalyst by lipolytic oleaginous yeast and biosurfactant-producing bacteria. Int Biodeterior Biodegrad 148: 104911. https://doi.org/10.1016/j.ibiod.2020.104911.

Magdouli S, Guedri T, Tarek R, Brar SK, Blais JF. 2017. Valorization of raw glycerol and crustacean waste into value added products by Yarrowia lipolytica. Bioresour Technol 243: 57-68. https://doi. org/10.1016/j.biortech.2017.06.074.

Magdouli S, Brar SK, Blais JF. 2018. Morphology and rheological behaviour of Yarrowia lipolytica: Impact of dissolved oxygen level on cell growth and lipid composition. Process Biochem 65: 1-10. https://doi.org/10.1016/j.procbio.2017.10.021.

Martins FF, Ferreira TF, Azevedo DA, Coelho MAZ. 2012. Evaluation of crude oil degradation by Yarrowia lipolytica. Chem Eng Trans 27: 223-228. https://doi.org/10.3303/ CET1227038.

Mat Aron NS, Khoo KS, Chew KW, Show PL, Chen WH, Nguyen THP. 2020. Sustainability of the four generations of biofuels - A review. Int J Energy Res 44(12): 9266-9282. https://doi.org/ 10.1002/er.5557.

Mathiazhakan K, Ayed D, Tyagi RD. 2016. Kinetics of lipid production at lab scale fermenters by a new isolate of Yarrowia lipolytica S KY7. Bioresour Technol 221: 234-240. https://doi. org/10.1016/j.biortech.2016.09.015.

Meng X, Yang J, Xu X, Zhang L, Nie Q, Xian M. 2009. Biodiesel production from oleaginous microorganisms. Renew Energy 34 (1): 1-5. https://doi.org/10.1016/j.renene.2008.04.014.

Meullemiestre A, Breil C, Abert-Vian M, Chemat F. 2016. Microwave, ultrasound, thermal treatments, and bead milling as intensification techniques for extraction of lipids from oleaginous Yarrowia lipolytica yeast for a biojetfuel application. Bioresour Technol 211: 190-199. https://doi.org/10.1016/j.bio rtech.2016.03.040.

Mlíčková K, Luo Y, D’Andrea S, Peč P, Chardot T, Nicaud JM. 2004. Acyl-CoA oxidase, a key step for lipid accumulation in the yeast Yarrowia lipolytica. J Mol Catal B: Enzym 28(2-3): 81-85. https://doi.org/10.1016/j.molcatb.2004.01.007.

Moreno LB. 2018. Cellular ecophysiology of microbe: Hydrocarbon and lipid interactions. In: Cellular Ecophysiology of Microbe: Hydrocarbon and Lipid Interactions. https://doi.org/10.1007/ 978-3-319-50542-8.

Morin N, Cescut J, Beopoulos A, et al. 2011. Transcriptomic analyses during the transition from biomass production to lipid accumulation in the oleaginous yeast Yarrowia lipolytica. PLoS ONE 6(11). https://doi.org/10.1371/journal.pone.0027966.

Nicaud J-M. 2012. Yarrowia lipolytica. Yeast 29: 409-418. https://doi. org/10.1002/yea.

Niehus X, Crutz-Le Coq AM, Sandoval G, Nicaud JM, Ledesma-Amaro R. 2018. Engineering Yarrowia lipolytica to enhance lipid production from lignocellulosic materials. Biotechnol Biofuels 11(1): 1-10. https://doi.org/10.1186/s13068-018-1010-6.

Papanikolaou S, Aggelis G. 2002. Lipid production by Yarrowia lipolytica growing on industrial glycerol in a single-stage continuous culture. Bioresour Technol 82(1): 43-49. https://doi. org/10.1016/S0960-8524(01)00149-3.
Papanikolaou S, Aggelis G. 2010. Yarrowia lipolytica: A model microorganism used for the production of tailor-made lipids. Eur J Lipid Sci Technol 112(6): 639-654. https://doi.org/10.1002/ ejlt.200900197.

Papanikolaou S, Chevalot I, Komaitis M, Aggelis G, Marc I. 2001. Kinetic profile of the cellular lipid composition in an oleaginous Yarrowia lipolytica capable of producing a cocoa-butter substitute from industrial fats. Antonie van Leeuwenhoek Int J Gen Mol Microbiol 80(3-4): 215-224. https://doi.org/10.1023/ A:1013083211405.

Papanikolaou S, Chevalot I, Komaitis M, Marc I, Aggelis G. 2002a. Single cell oil production by Yarrowia lipolytica growing on an industrial derivative of animal fat in batch cultures. Appl Microbiol Biotechnol 58(3): 308-312. https://doi.org/10.1007/ s00253-001-0897-0.

Papanikolaou S, Muniglia L, Chevalot I, Aggelis G, Marc I. 2002b. Yarrowia lipolytica as a potential producer of citric acid from raw glycerol. J Appl Microbiol 92(4): 737-744. https://doi.org/ 10.1046/j.1365-2672.2002.01577.x.

Papanikolaou S, Muniglia L, Chevalot I, Aggelis G, Marc I. 2003. Accumulation of a cocoa-butter-like lipid by Yarrowia lipolytica cultivated on agro-industrial residues. Curr Microbiol 46(2): 124-130. https://doi.org/10.1007/s00284-002-3833-3.

Papanikolaou S, Chevalot I, Galiotou-Panayotou M, Komaitis M, Marc I, Aggelis G. 2007. Industrial derivative of tallow: A promising renewable substrate for microbial lipid, single-cell protein and lipase production by Yarrowia lipolytica. Electron $J$ Biotechnol 10(3): 425-435. https://doi.org/10.2225/vol10issue3-fulltext-8.

Papanikolaou S, Chatzifragkou A, Fakas S, et al. 2009. Biosynthesis of lipids and organic acids by Yarrowia lipolytica strains cultivated on glucose. Eur J Lipid Sci Technol 111(12): 12211232. https://doi.org/10.1002/ejlt.200900055.

Paschalidou A, Tsatiris M, Kitikidou K. 2016. Energy crops for biofuel production or for food?-SWOT analysis (case study: Greece). Renew Energy 93: 636-647. https://doi.org/10.1016/j. renene.2016.03.040.

Patel A, Mikes F, Matsakas L. 2018. An overview of current pretreatment methods used to improve lipid extraction from oleaginous microorganisms. Molecules 23(7). https://doi.org/ 10.3390/molecules23071562.

Patrignani F, Vannini L, Gardini F, Guerzoni ME, Lanciotti R. 2011. Variability of the lipolytic activity and volatile molecules production by a strain of Yarrowia lipolytica in pork fat and its dependence on environmental conditions. Meat Sci 89(1): 21-26. https://doi.org/10.1016/j.meatsci.2011.03.015.

Poli JS, Dallé P, Senter L, et al. 2013. Fatty acid methyl esters produced by oleaginous yeast Yarrowia lipolytica QU21: an alternative for vegetable oils. Braz J Biosci 1985: 203-208.

Poli JS, da Silva MAN, Siqueira EP, Pasa VMD, Rosa CA, Valente P. 2014. Microbial lipid produced by Yarrowia lipolytica QU21 using industrial waste: A potential feedstock for biodiesel production. Bioresour Technol 161(2014): 320-326. https://doi. org/10.1016/j.biortech.2014.03.083.

Poontawee R, Limtong S. 2020. Feeding strategies of two-stage fedbatch cultivation processes for microbial lipid production from sugarcane top hydrolysate and crude glycerol by the oleaginous red yeast Rhodosporidiobolus fluvialis. Microorganisms 8(2): 151. https://doi.org/10.3390/microorganisms8020151.

Qiao K, Imam Abidi SH, Liu H, et al. 2015. Engineering lipid overproduction in the oleaginous yeast Yarrowia lipolytica. Metab Eng 29: 56-65. https://doi.org/10.1016/j.ymben.2015.02.005.

Qiao K, Wasylenko TM, Zhou K, Xu P, Stephanopoulos G. 2017. Lipid production in Yarrowia lipolytica is maximized by 
engineering cytosolic redox metabolism. Nat Biotechnol 35(2): 173-177. https://doi.org/10.1038/nbt.3763.

Qin L, Liu L, Zeng AP, Wei D. 2017. From low-cost substrates to single cell oils synthesized by oleaginous yeasts. Bioresour Technol 245: 1507-1519. https://doi.org/10.1016/j.bio rtech.2017.05.163.

Rakicka M, Lazar Z, Dulermo T, Fickers P, Nicaud JM. 2015. Lipid production by the oleaginous yeast Yarrowia lipolytica using industrial by-products under different culture conditions. Biotechnol Biofuels 8(1): 1-10. https://doi.org/10.1186/ s13068-015-0286-z.

Ratledge C. 2014. The role of malic enzyme as the provider of NADPH in oleaginous microorganisms: A reappraisal and unsolved problems. Biotechnol Lett 36(8): 1557-1568. https:// doi.org/10.1007/s10529-014-1532-3.

Sagnak R, Cochot S, Molina-Jouve C, Nicaud JM, Guillouet SE. 2018. Modulation of the Glycerol Phosphate availability led to concomitant reduction in the citric acid excretion and increase in lipid content and yield in Yarrowia lipolytica. J Biotechnol 265: 40-45. https://doi.org/10.1016/j.jbiotec.2017.11.001.

Sara M, Brar SK, Blais JF. 2016. Lipid production by Yarrowia lipolytica grown on biodiesel-derived crude glycerol: Optimization of growth parameters and their effects on the fermentation efficiency. RSC Adv 6(93): 90547-90558. https://doi.org/10.1039/ c6ra16382c.

Sarantou S, Stoforos NG, Kalantzi O, Papanikolaou S. 2021. Biotechnological valorization of biodiesel-derived glycerol: Trials with the non-conventional yeasts Yarrowia lipolytica and Rhodosporidium sp. Carbon Resourc Convers 4: 61-75. https:// doi.org/10.1016/j.crcon.2020.12.006.

Seip J, Jackson R, He H, Zhu Q, Hong SP. 2013. Snf1 is a regulator of lipid accumulation in Yarrowia lipolytica. Appl Environ Microbiol 79(23): 7360-7370. https://doi.org/10.1128/AEM.02079-13.

Sekova VY, Dergacheva DI, Isakova EP, Gessler NN, Tereshina VM, Deryabina YI. 2019. Soluble sugar and lipid readjustments in the Yarrowia lipolytica yeast at various temperatures and ph. Metabolites 9(12). https://doi.org/10.3390/metabo9120307.

Shitu A, Izhar S, Tahir TM. 2015. Sub-critical water as a green solvent for production of valuable materials from agricultural waste biomass: A review of recent work. Global J Environ 1(3): 255-264.

Silverman AM, Qiao K, Xu P, Stephanopoulos G. 2016. Functional overexpression and characterization of lipogenesis-related genes in the oleaginous yeast Yarrowia lipolytica. Appl Microbiol Biotechnol 100(8): 3781-3798. https://doi.org/10.1007/ s00253-016-7376-0.

Singh A, Olsen SI, Nigam PS. 2011. A viable technology to generate third-generation biofuel. J Chem Technol Biotechnol 86(11): 1349-1353. https://doi.org/10.1002/jctb.2666.

Tai M, Stephanopoulos G. 2013. Engineering the push and pull of lipid biosynthesis in oleaginous yeast Yarrowia lipolytica for biofuel production. Metab Eng 15(1): 1-9. https://doi.org/ 10.1016/j.ymben.2012.08.007.

Tan T, Lu J, Nie K, Deng L, Wang F. 2010. Biodiesel production with immobilized lipase: A review. Biotechnol Adv 28(5): 628-634. https://doi.org/10.1016/j.biotechadv.2010.05.012.

Taoka Y, Nagano N, Okita Y, Izumida H, Sugimoto S, Hayashi M. 2011. Effect of Tween 80 on the growth, lipid accumulation and fatty acid composition of Thraustochytrium aureum ATCC 34304. J Biosci Bioeng 111(4): 420-424. https://doi.org/ 10.1016/j.jbiosc.2010.12.010.

Tchakouteu SS, Kalantzi O, Gardeli C, Koutinas AA, Aggelis G, Papanikolaou S. 2015. Lipid production by yeasts growing on biodiesel-derived crude glycerol: Strain selection and impact of substrate concentration on the fermentation efficiency. $J$ Appl Microbiol 118(4): 911-927. https://doi.org/10.1111/jam.12736.

Thiru M, Sankh S, Rangaswamy V. 2011. Process for biodiesel production from Cryptococcus curvatus. Bioresour Technol 102 (22): 10436-10440. https://doi.org/10.1016/j.bio rtech.2011.08.102.

Tran Nguyen PL, Go AW, Huynh LH, Ju YH. 2013. A study on the mechanism of subcritical water treatment to maximize extractable cellular lipids. Biomass Bioenergy 59: 532-539. https://doi.org/ 10.1016/j.biombioe.2013.08.031.

Tribst AAL, Franchi MA, Cristianini M. 2008. Ultra-high pressure homogenization treatment combined with lysozyme for controlling Lactobacillus brevis contamination in model system. Innovat Food Sci Emerg Technol 9(3): 265-271. https://doi.org/10.1016/j. ifset.2007.07.012.

Tsigie YA, Wang CY, Truong CT, Ju YH. 2011. Lipid production from Yarrowia lipolytica Polg grown in sugarcane bagasse hydrolysate. Bioresour Technol 102(19): 9216-9222. https://doi.org/ 10.1016/j.biortech.2011.06.047.

Tsigie YA, Huynh LH, Ahmed IN, Ju YH. 2012. Maximizing biodiesel production from Yarrowia lipolytica Polg biomass using subcritical water pretreatment. Bioresour Technol 111: 201207. https://doi.org/10.1016/j.biortech.2012.02.052.

Wang ZP, Xu HM, Wang GY, Chi Z, Chi ZM. 2013. Disruption of the MIG1 gene enhances lipid biosynthesis in the oleaginous yeast Yarrowia lipolytica ACA-DC 50109. Biochim Biophys Acta-Mol Cell Biol Lipids 1831(4): 675-682. https://doi.org/10.1016/j. bbalip.2012.12.010.

Wang G, Li D, Miao Z, Zhang S, Liang W, Liu L. 2018. Comparative transcriptome analysis reveals multiple functions for Mhylp in lipid biosynthesis in the oleaginous yeast Yarrowia lipolytica. Biochim Biophys Acta-Mol Cell Biol Lipids 1863(1): 81-90. https://doi.org/10.1016/j.bbalip.2017.10.003.

Wang ZP, Wang QQ, Liu S, Liu XF, Yu XJ, Jiang YL. 2019. Efficient conversion of cane molasses towards high-purity isomaltulose and cellular lipid using an engineered Yarrowia lipolytica strain in fed-batch fermentation. Molecules 24(7). https://doi.org/10.3390/ molecules24071228.

Wang J, Ledesma-Amaro R, Wei Y, Ji B, Ji XJ. 2020. Metabolic engineering for increased lipid accumulation in Yarrowia lipolytica-A review. Bioresour Technol 313. https://doi.org/ 10.1016/j.biortech.2020.123707.

Wasylenko TM, Ahn WS, Stephanopoulos G. 2015. The oxidative pentose phosphate pathway is the primary source of NADPH for lipid overproduction from glucose in Yarrowia lipolytica. Metab Eng 30: 27-39. https://doi.org/10.1016/j.ymben.2015.02.007.

Wei S, Jian X, Chen J, Zhang C, Hua Q. 2017. Reconstruction of genome-scale metabolic model of Yarrowia lipolytica and its application in overproduction of triacylglycerol. Bioresour Bioprocess 4(1). https://doi.org/10.1186/s40643-017-0180-6.

Xie D. 2017. Integrating cellular and bioprocess engineering in the non-conventional yeast Yarrowia lipolytica for biodiesel production: A review. Front Bioeng Biotechnol 5. https://doi.org/ 10.3389/fbioe.2017.00065.

Xu P, Qiao K, Stephanopoulos G. 2017. Engineering oxidative stress defense pathways to build a robust lipid production platform in Yarrowia lipolytica. Biotechnol Bioeng 114(7): 1521-1530. https://doi.org/10.1002/bit.26285.

Xua P, Qiao K, Ahn WS, Stephanopoulos G. 2016. Engineering Yarrowia lipolytica as a platform for synthesis of drop-in transportation fuels and oleochemicals. Proc Natl Acad Sci USA 113(39): 10848-10853. https://doi.org/10.1073/ pnas. 1607295113 . 
Xue J, Balamurugan S, Li T, et al. 2021. Biotechnological approaches to enhance biofuel producing potential of microalgae. Fuel 302: 121169. https://doi.org/10.1016/j.fuel.2021.121169.

Yan FX, Dong GR, Qiang S, Niu YJ, Hu CY, Meng YH. 2020. Overexpression of $\triangle 12, \triangle 15$-Desaturases for Enhanced Lipids Synthesis in Yarrowia lipolytica. Front Microbiol 11: 1-11. https://doi.org/10.3389/fmicb.2020.00289.

Yap BHJ, Dumsday GJ, Scales PJ, Martin GJO. 2015. Energy evaluation of algal cell disruption by high pressure homogenisation. Bioresour Technol 184: 280-285. https://doi.org/10.1016/j. biortech.2014.11.049.

Yook S Do Kim J, Gong G, et al. 2020. High-yield lipid production from lignocellulosic biomass using engineered xylose-utilizing Yarrowia lipolytica. GCB Bioenergy 12(9): 670-679. https://doi. org/10.1111/gcbb.12699.

Zhang Y, Adams IP, Ratledge C. 2007. Malic enzyme: The controlling activity for lipid production? Overexpression of malic enzyme in Mucor circinelloides leads to a 2.5 -fold increase in lipid accumulation. Microbiology 153(7): 2013-2025. https://doi.org/ 10.1099/mic.0.2006/002683-0.

Zhang H, Zhang L, Chen H, et al. 2014. Enhanced lipid accumulation in the yeast Yarrowia lipolytica by over-expression of ATP: Citrate lyase from Mus musculus. J Biotechnol 192(Part A): 7884. https://doi.org/10.1016/j.jbiotec.2014.10.004.

Zhang H, Kang X, Xiao N, et al. 2019a. Intracellular expression of Vitreoscilla haemoglobin improves lipid production in Yarrowia lipolytica. Lett Appl Microbiol 68(3): 248-257. https://doi.org/ 10.1111/lam.13111.

Zhang S, Jagtap SS, Deewan A, Rao CV. 2019b. pH selectively regulates citric acid and lipid production in Yarrowia lipolytica W29 during nitrogen-limited growth on glucose. J Biotechnol 290: 10-15. https://doi.org/10.1016/j.jbiotec.2018.10.012.

Zieniuk B, Fabiszewska A. 2019. Yarrowia lipolytica: a beneficious yeast in biotechnology as a rare opportunistic fungal pathogen: A mini review. World J Microbiol Biotechnol 35(1): 1-8. https://doi. org/10.1007/s11274-018-2583-8.

Cite this article as: El Kantar S, Khelfa A, Vorobiev E, Koubaa M. 2021. Strategies for increasing lipid accumulation and recovery from Y. lipolytica: A review. OCL 28: 51. 